\title{
GRABADOS RUPESTRES, PAISAJE Y PRÁCTICAS SOCIALES EN LA CUENCA DEL RÍO DE LAS TUNAS (MENDOZA, ARGENTINA)
}

\author{
ROCK ENGRAVINGS, LANDSCAPES AND SOCIAL PRACTICES \\ IN THE LAS TUNAS RIVER BASIN (MENDOZA, ARGENTINA)
}

María José Otsa, Andrés Rochab, Lourdes Iniestac \& Pablo Cahiza

Los grabados rupestres del sitio La Pampa constituyen un conjunto de 794 incisiones lineales, hoyuelos y tacitas conjuntodistribuido en 25 rocas al aire libre. Se realizó un registro de los soportes y sus representaciones con el objetivo de reconocer su configuración espacial interna y contextual en tres escalas: la roca, el sitio y la microrregión. Se interpreta este lugar con una funcionalidad ritual específica, cuyo emplazamiento en relación con rutas de tránsito microrregional conecta sitios de actividades múltiples localizados en dos sectores contrapuestos: la cordillera hacia el oeste y el oasis pedemontano hacia el este.

Palabras clave: Arqueología del paisaje, Grabados, Morteros, Valle de Uco, Mendoza.

The rock engravings of the La Pampa site, in the foothills of the Las Tunas River basin, include a set of 794 incisions, cavities and cups distributed on 25 open-air rocks. The supports and their representations were recorded to identify their internal and contextual spatial configuration, on three scales -rock, site and microregion. The site is interpreted as having a specific ritual functionality and was located in association with microregional transit routes that connected multiple activity sites located in two contrasting environments- the western mountains and the eastern piedmont oasis.

Keywords: Landscape archaelogy, Engravings, Mortar, Valle de Uco, Mendoza.

\section{INTRODUCCIÓN}

Las representaciones rupestres son producto de determinadas prácticas sociales que permiten la apropiación del paisaje (Criado Boado 1999, Anschuetzs et al. 2001). En este sentido, los sitios poseen una lógica que se expresa a través de la organización y la ordenación del espacio. A la vez, son parte de una red de relaciones que implican no solo las acciones prácticas de la sociedad que ocupó un lugar concreto, sino también la interrelación simbólica con el espacio circundante (Tilley 1996, Thomas 2001, Rocha 2017a).

El sitio La Pampa se localiza en el piedemonte a $33^{\circ} 28^{\prime} 33,8^{\prime \prime S} 69^{\circ} 13^{\prime} 35,5^{\prime \prime} \mathrm{O}$, a $1250 \mathrm{msnm}$, en un cono de deyección que drena el Río de las Tunas cuyo caudal, en este sector, se infiltra dejando múltiples cauces que se activan temporalmente. Está compuesto por un conjunto de 25 rocas al aire libre distribuidas en una superficie de 24,8 ha, con distinto tipo de grabados: tacitas, oquedades e incisiones lineales. Algunas de estas manifestaciones rupestres son características de otros sectores de la

\footnotetext{
A María José Ots, Incinusa-Conicet, IAye- Facultad de Filosofía y Letras, Universidad Nacional de Cuyo, Mendoza, Argentina. E-mail: mjots@mendoza-conicet.gob.ar

B Andrés Rocha, Facultad de Filosofía y Letras, Universidad Nacional de Cuyo, Mendoza, Argentina. E-mail: aztlan1456@gmail.com

C Lourdes Iniesta, Facultad de Filosofía y Letras, Universidad Nacional de Cuyo, Mendoza, Argentina. E-mail: luiniesta9@hotmail.com

D Pablo Cahiza, IncinusA-Conicet, IAyE- Facultad de Filosofía y Letras, Universidad Nacional de Cuyo, Mendoza. Argentina. E-mail: pcahiza@mendoza-conicet.gob.ar
} 


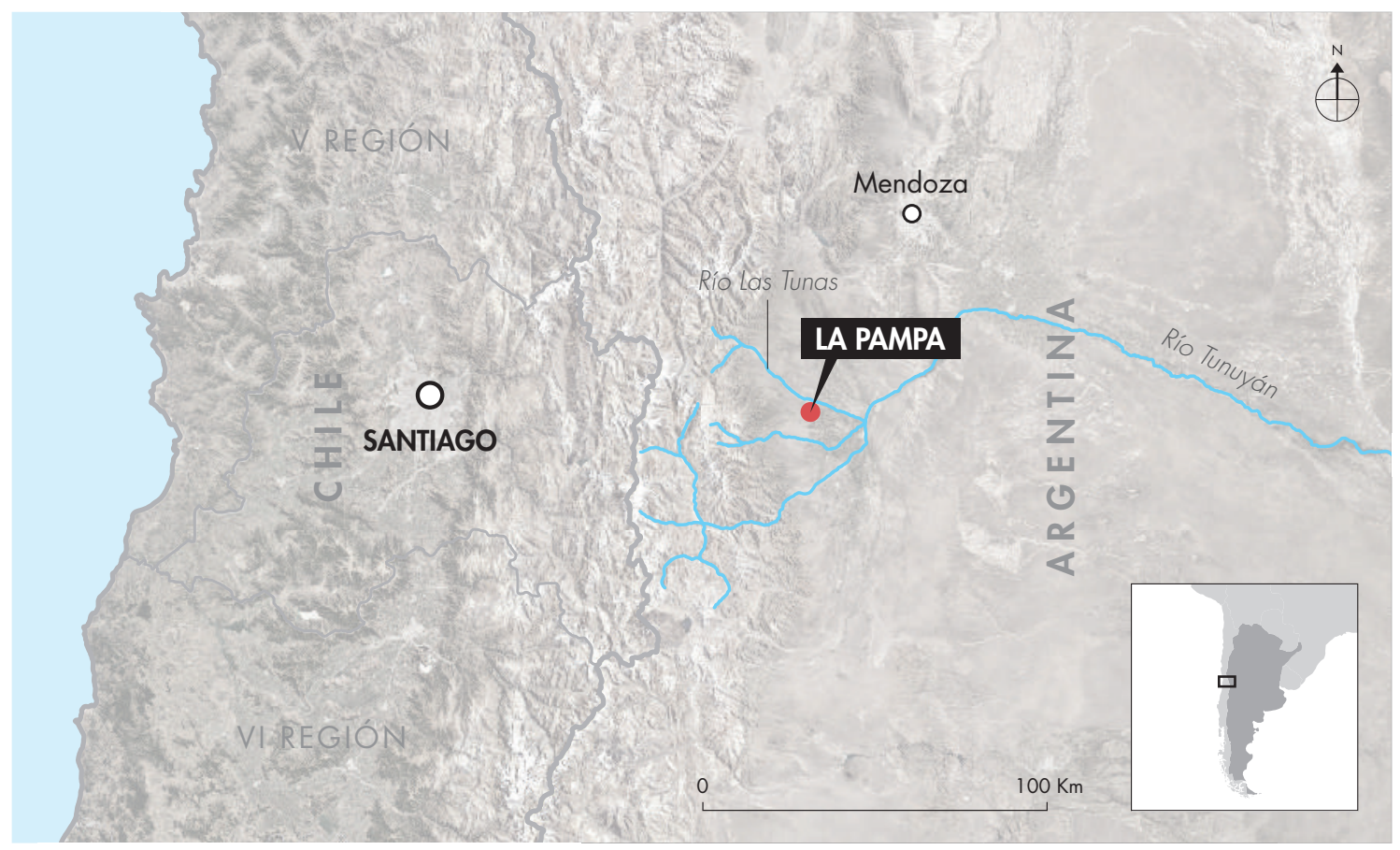

Figura 1. Localización del sitio La Pampa. Figure 1. Location of the La Pampa site.

macrorregión centro-oeste argentino-Chile central, en tanto que otras, por el contrario, son novedosas.

El estudio de este sitio es parte de las investigaciones que realizamos en la microrregión comprendida por la cuenca del Río de las Tunas (Valle de Uco, Mendoza) (figs. 1 y 2) y que tienen por objetivo general conocer las continuidades y las transformaciones de las estrategias humanas y la ocupación del espacio (Ots 2005, 2007). Es por ello que el análisis de las representaciones rupestres se realizó desde un enfoque espacial multiescalar, a partir de la observación particular de cada roca y de su integración en el sitio y en la microrregión.

El centro de Mendoza no cuenta con antecedentes relevantes de manifestaciones rupestres, al contrario de lo que se conoce para otros sectores del centro oeste argentino, como en la provincia de San Juan y en el noroeste y sur de Mendoza (sintetizados, por ejemplo, en Lagiglia 1997 y Schobinger 2009). Se han reconocido sitios con piedras tacitas en algunos sectores del Valle de Uco (arroyo del Novillo Muerto en la cuenca del Río de las Tunas, Viluco y Paso de las Carretas en la cuenca del Tunuyán), como una manifestación particular del área (Schobinger \& Gradin 1985, Lagiglia 1997), similar a la que se reconoce en el centro y norte de Chile (entre otros, Gajardo Tobar 1959, Hermosilla \& Ramírez 1985, Planella et al. 2017, Troncoso et al. 2017). En el sur de la Provincia, en el Departamento de Malargüe, también se encuentran morteros o tacitas asociados a representaciones grabadas (Schobinger 2009).

Los otros motivos representados, oquedades pequeñas e incisiones lineales rectas y profundas, en cambio, solo tienen un antecedente en la región en el sitio Agua de la Tinaja I (valle de Uspallata, Mendoza), donde se hallaron tres incisiones y una oquedad pequeña grabadas en el piso de roca en un nivel fechado en $4510 \pm 130$ в (3620-2780 cal. BC) (Bárcena et al. 1985: 353-354 y lám. I c). Motivos similares se encuentran en otras regiones, por ejemplo, el Noroeste Argentino y las sierras centrales de Argentina en las que se han reconocido oquedades pequeñas, como en Abra de los Morteros, Jujuy y varios sitios de la Pampa de Achala y Río Cuarto en Córdoba (Fernández Distel 1994, Ponzio \& Reinoso 2013, Recalde 2015, entre otros). También se han registrado incisiones lineales paralelas en sitios tempranos de la Patagonia (vg. Epullan Grande, Arias et al. 2012); sin embargo, no se asemejan al caso de La Pampa.

El carácter particular de estas representaciones permite definir los objetivos específicos de nuestra 


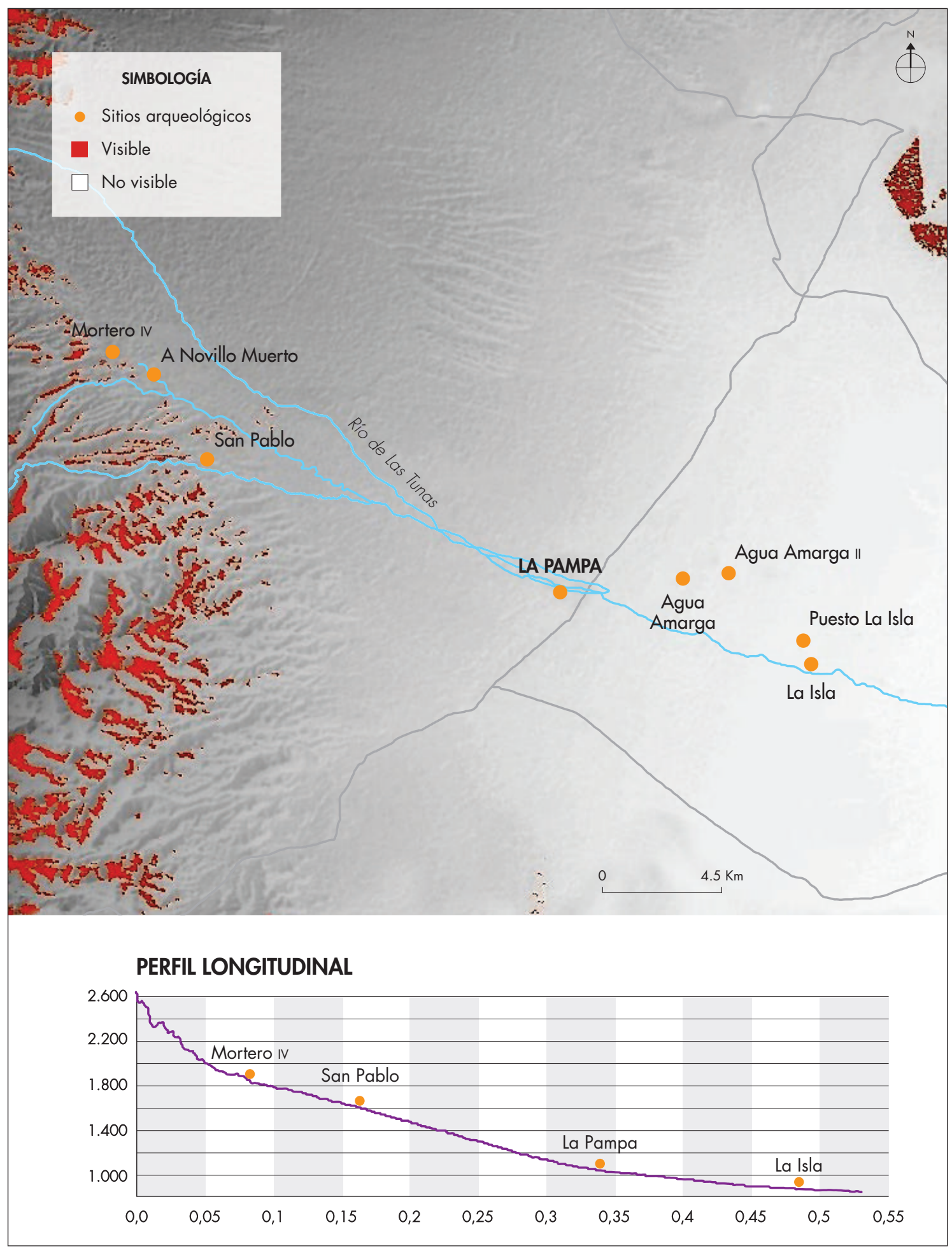

Figura 2. Detalle de visibilidad desde el sitio La Pampa en la microrregión cuenca del Río de las Tunas. Localización de los sitios y esquema del perfil longitudinal. Figure 2. Detail of visibility from the La Pampa site in the Las Tunas River basin. Location of sites and longitudinal profile. 
investigación: realizar un registro de los soportes y sus representaciones y, en el marco de la arqueología del Paisaje (Criado Boado 1999), reconocer su configuración espacial interna y contextual.

\section{PAISAJE, PRÁCTICAS Y GRABADOS EN EL RÍO DE LAS TUNAS}

Las representaciones rupestres forman parte de la dimensión social del paisaje, son materialidades que se encuentran articuladas e interrelacionadas con el espacio pensado y/o significado. Imprimen un sello en los espacios debido a que son artefactos inmuebles y algunas veces monumentales, implican la modificación del entorno natural para su realización y tienen atributos de visibilidad y persistencia a lo largo del tiempo (Podestá et al. 1991, Valenzuela et al. 2006: 207).

La selección y el acondicionamiento de las rocas con una determinada configuración espacial forman parte de una arquitectura $o$

tecnología de construcción del paisaje social que mediante dispositivos artificiales domestica el mundo físico no solo introduciendo hitos arquitectónicos en el espacio natural para ordenarlo según referencias culturales, sino también controlando e imponiendo la pauta de percepción del entorno por parte de los individuos que la usan (Criado Boado 1999: 35).

Es por ello que, desde nuestra perspectiva, el estudio de estas representaciones debe abordarse desde la arqueología espacial, que concibe el paisaje como una construcción de las prácticas sociales y culturales y de la vida social (Criado Boado 1993a), y considera que los rasgos formales de la cultura material arqueológica reproducen los modelos de representación y construcción del espacio vigentes en cada sociedad concreta. El paisaje es la objetivación de una intencionalidad, a la cual podemos intentar aproximarnos a partir de la deconstrucción de los elementos que lo componen (Criado Boado 1999) y de establecer sus posibles relaciones, ya que el significado se produce a través del funcionamiento dinámico de las relaciones entre personas, cosas y lugares (Thomas 2001).

Siguiendo estas propuestas, las herramientas metodológicas que utilizamos para lograr esta deconstrucción se basan en el análisis de los motivos particulares, su disposición, su asociación con el registro arqueológico y las relaciones y patrones espaciales de las rocas grabadas a partir de múltiples escalas espaciales.

\section{Antecedentes microrregionales: arqueología de la cuenca del Río de las Tunas}

El Río de las Tunas es uno de los pocos del área que en tiempos coloniales conservaba su nombre indígena, Allallpoto (río de la Plata, según el vocabulario del P. Valdivia 1943 [1608]). Se origina en la cordillera frontal, es de caudal permanente y abundante, disminuido en el piedemonte por su aprovechamiento aguas arriba para riego. En su trayectoria conecta los ambientes de cordillera, piedemonte y planicie, conformando una microrregión que permite estudiar patrones de distribución espacial de las ocupaciones humanas en la larga duración.

El paisaje cordillerano se caracteriza por vertientes, aguadas y arroyos permanentes, suelos muy húmedos, vegas y abundante vegetación (Adesmia). En el piedemonte, el cauce principal del Río de las Tunas confluye con cursos permanentes que nacen en la cordillera y arroyos que surgen en la depresión alimentados con aguas subterráneas. La vegetación es de Larrea divaricata y Piptochaetium napostaense. El sector pedemontano se presenta como un glacis cubierto por una espesa capa de materiales que desciende hasta los 1200-800 msnm, con limos de origen aluvial y tectónico aptos para agricultura. Hacia el este, la planicie se caracteriza por el paisaje desértico, eólico, con grandes cadenas de médanos cubiertos por la vegetación propia de la "Provincia Fitogeográfica del Monte" (Prosopisflexuosa, Larrea divaricata, Atriplex lampa).

A partir de la prospección pedestre de la microrregión y del estudio de sitios, reconocimos un patrón de ocupación espacial diacrónico, por el que distinguimos las ocupaciones del componente Alfarero Medio (fechado en este sector en ca. 1500-600 AP) del Tardío-incaico (ca. 600-400 AP). En el sector cordillerano se localizan sitios del Período Alfarero Medio de tamaño reducido (menor a tres hectáreas), asociados a artefactos y estructuras de molienda. Estos son sitios de ocupación estacional al aire libre y de propósitos específicos (caza, recolección y procesamiento de alimentos). En tanto que, en el sector pedemontano, los asentamientos del mismo período son de mayor tamaño (más de seis hectáreas). Los sitios tardíos se concentran en este último sector, alrededor de los $1000 \mathrm{msnm}$, y reocupan asentamientos previos, pero son de mayor tamaño (entre 9 y 52 hectáreas) (Ots 2007). Interpretamos que los sitios del piedemonte son 
residenciales de ocupación permanente y de múltiples actividades que incluyen la horticultura (Cahiza \& Ots 2014, Ots et al. 2016).

Estas comunidades se pueden caracterizar como sociedades de pequeña escala (Cahiza \& Ots 2014, Reyes García et al. 2017, entre otros), definidas en términos demográficos como grupos de baja densidad de población. En cuanto a las relaciones sociales, estas se caracterizan por la interacción igualitaria entre los individuos y el contacto durante la vida cotidiana. A nivel político, por sistemas descentralizados o que mantienen la autonomía de una o pocas comunidades locales. En lo económico se caracterizan por la cooperación para la producción (Reyes García et al. 2017) y, en este caso, por una organización de subsistencia de base mixta, cazadora-recolectora y con aporte de la estrategia productiva en el sector pedemontano.

\section{METODOLOGÍA}

Para describir y analizar las relaciones entre los elementos del paisaje, el estudio de las representaciones rupestres se abordó desde tres escalas de análisis (entre otros, Aschero 1997). Se tomó como unidad mínima de registro a cada roca/soporte (primera escala), luego se consideró la distribución espacial de las rocas en el sitio y sus relaciones (entre sí y con el resto de las evidencias) (segunda escala) y finalmente se integraron estos resultados con las investigaciones que se están realizando en la microrregión que conforma la cuenca del Río de Las Tunas (tercera escala).

En la primera escala de estudio se realizó un análisis formal de los grabados y las rocas. Las evidencias arqueológicas (soportes grabados y otros restos materiales) se localizaron a través de prospecciones pedestres sistemáticas en un área de $6,9 \mathrm{~km}^{2}$. Se llevó a cabo el registro métrico, morfológico, de distribución y fotográfico de cada soporte. Se clasificó cada uno a través de fichas técnicas que consignan morfología de las representaciones, cantidad, medidas (profundidad, longitud y/o diámetro), distribución en la superficie de las rocas y técnicas de producción. También se registraron las características físicas de los soportes: tipo de roca, medidas de los extremos y georreferenciación por medio del sistema de posicionamiento global (GPS) en coordenadas geográficas en el sistema wGS 84 . Cada roca fue dibujada utilizando las herramientas del pro- grama Adobe Ilustrator y se tomó como referencia la vista superior.

En la segunda escala de análisis se estudió la distribución espacial del registro arqueológico y la topografía del sitio. Para ello, se consideraron datos ambientales que pudieran ser relevantes para las interpretaciones: traza de cauces, vegetación, altura y declinación del terreno y otros elementos topográficos (según la carta del IGN a escala 1:250.000). Los datos arqueológicos complementarios del análisis de las rocas se optuvieron mediante la recolección superficial sistemática de restos y la excavación de $13 \mathrm{~m}^{2}$ distribuidos en el sector de mayor concentración de rocas y de materiales en superficie.

Se analizó la distribución de las rocas y de los motivos representados mediante la aplicación de estadística geoespacial de interpolación con el método kriging (Wheatley \& Gillings 2002). Se utilizaron las coordenadas de localización UTM (Universal Transversal Mercator) para establecer las distancias euclidianas y datos $\mathrm{XY}$, en tanto la frecuencia de motivos por roca fueron considerados valor $Z$. Los datos se procesarons en el software Golden Surfer 8 con la función grid/kriging proyectada en imágenes $3 \mathrm{D}$.

Finalmente, en la tercera escala de análisis se estudiaron las asociaciones con el ambiente y los contextos arqueológicos microrregionales que fueron sintetizados en los antecedentes.

Tanto la escala de sitio (segunda escala) como la microrregional (tercera escala) tienen en cuenta la visibilidad y las rutas entre los grabados y con distintos elementos del paisaje que los interconectan. La movilidad y la percepción visual son esenciales para comprender la relación humana con el entorno, ya que permiten acceder a las lógicas que hay detrás de la estructura organizacional de una sociedad (Criado Boado 1993b, Fábrega-Álvarez 2016).

Para ello, se hizo el análisis de cuenca visual o viewshed, herramienta proporcionada por el software ArcGis 10.3. Esta herramienta es útil para identificar qué rasgos del paisaje son visibles desde el sitio. La cuenca visual se calcula al comparar el ángulo de altitud de un punto con el ángulo de altitud hacia el horizonte local y tiene en cuenta la topografía del terreno que interviene entre el punto de observación y la distancia considerada. Cada celda del ráster de salida recibe un valor que indica cuántos puntos de observador pueden verse desde una ubicación (en este caso, una de las concentraciones del sitio La Pampa localizado con GPs) considerando 
el modelo digital de terreno (obtenido de una imagen satelital ASTER). Se otorgó un valor de 1 a cada celda que puede visualizarse desde un punto de observación, $y$ de 0 en caso contrario.

Para el análisis de tránsito, se registró el track con GPS de las sendas que interconectan los diferentes sectores del sitio y las rocas con grabados. El estudio de las rutas de tránsito o caminos que unen diferentes puntos arqueológicos comprende diversos aspectos, como las escalas espaciales, la accesibilidad, las dificultades del terreno, las prácticas culturales, etcétera (Fábrega-Álvarez 2016). En este trabajo buscamos analizar el desplazamiento en su relación con las estrategias de circulación, percepción y conexión entre diferentes direcciones.

\section{Primera escala: análisis de rocas con grabados}

Sintetizaremos los principales resultados de este análisis, que ha sido desarrollado extensamente por Rocha (2017 a y b). Se registraron y posicionaron 25 rocas de distinto tamaño y forma con grabados (denominadas LP1 a LP25) (fig. 3 y tabla 1), las cuales tienen una orientación específica este-oeste/norte-sur. La mayoría de los soportes intervenidos son rocas metamórficas (24 son esquistos), y una única roca es ígnea. Estas son producto de metamorfismo regional, han sido trasladadas desde la cordillera por los aluviones del Río de Las Tunas y se encuentran distribuidas por toda la zona.

Se registraron en total 794 grabados (tabla 1). Las representaciones son no figurativas, geométricas. En principio, se distinguen dos tipos: lineales y circulares u ovales. Los grabados lineales representan el $47 \%$. En estos casos, la técnica que se utilizó es la de incisión, probablemente realizada con un artefacto filoso (Álvarez \& Fiore 1995). Mediante un corte o hendidura en la superficie de la roca se produjo un estrechamiento hacia la base de la incisión que culmina en forma angular y deja un surco en forma de V. Algunas de estas incisiones son más profundas, anchas y de lados convergentes en $\mathrm{V}$ pulidos, lo que sugiere una o varias intervenciones posteriores (figs. $4 \mathrm{~b}$ y 5). Algunas alcanzan hasta $3,9 \mathrm{~cm}$ de profundidad. Las diferencias en cuanto a longitud, ancho y profundidad de los grabados incisos se encuentran combinadas en todos los soportes, en algunos casos solo presentan incisiones finas y poco profundas (LP12 y LP16), mientras que en el resto las hay de diferentes tamaños en una misma roca que alcanzan, por ejemplo, $57 \mathrm{~cm}$ de longitud y $3 \mathrm{~cm}$ de profundidad en LP24 (tabla 1 y figs. 4, 5 y 6). No encontramos un patrón en la orientación de las incisiones, que se encuentran dispuestas en distintas direcciones.

Entre los grabados circulares distinguimos, por tamaño de diámetro y profundidad, las oquedades circulares pequeñas (también llamadas "hoyuelos", v.g. Ponzio \& Reinoso 2013, Recalde 2015) de las tacitas o concavidades más profundas. Las técnicas de grabado pudieron ser machacado y horadación (Álvarez \& Fiore 1995). Las oquedades representan el $39 \%$ de grabados. Su tamaño oscila entre 2 y $4 \mathrm{~cm}$ de diámetro y 1 y $3 \mathrm{~cm}$ de profundidad. En tanto que las tacitas representan el 14\% de grabados y tienen forma circular y oval. Las circulares miden entre 6 y $13 \mathrm{~cm}$ de diámetro y entre 2 y $5 \mathrm{~cm}$ de profundidad. Todas conforman una tacita cóncava bien

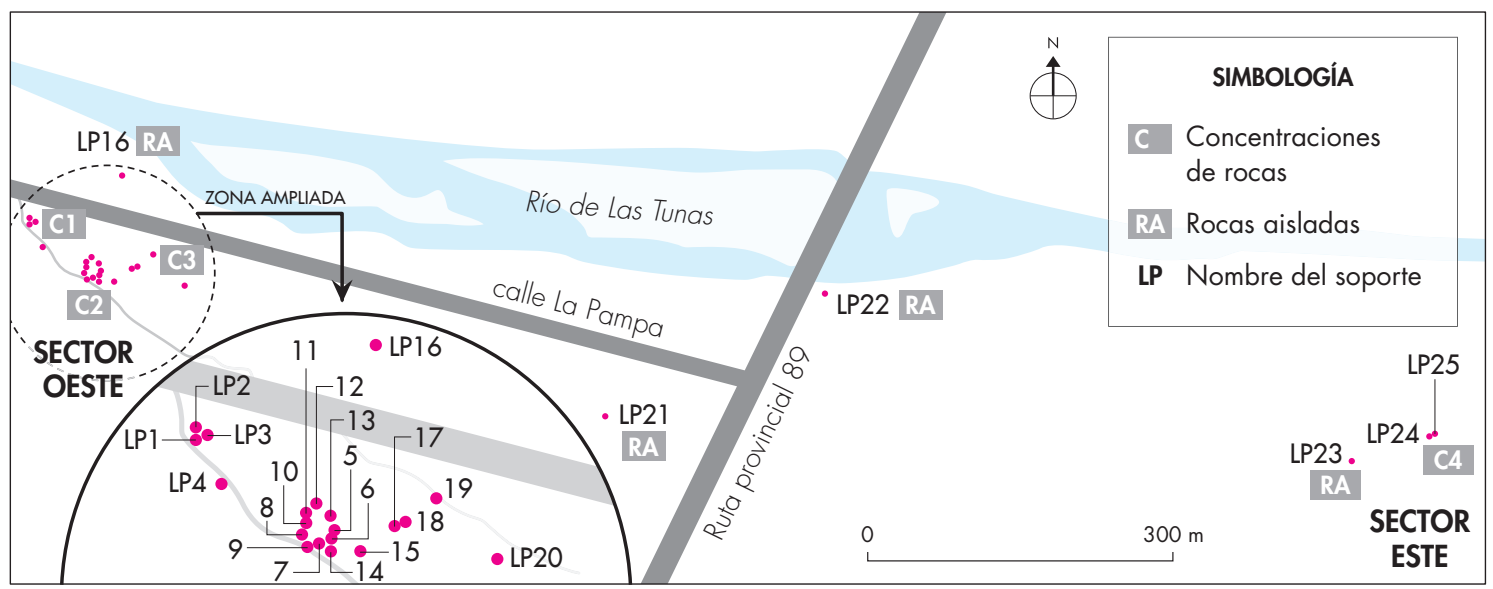

Figura 3. Plano de distribución de soportes en La Pampa. Figure 3. Distribution of supports at the La Pampa site. 
Tabla 1. Frecuencia de grabados y tipo por roca. Table 1. Engraving frequency and rock type.

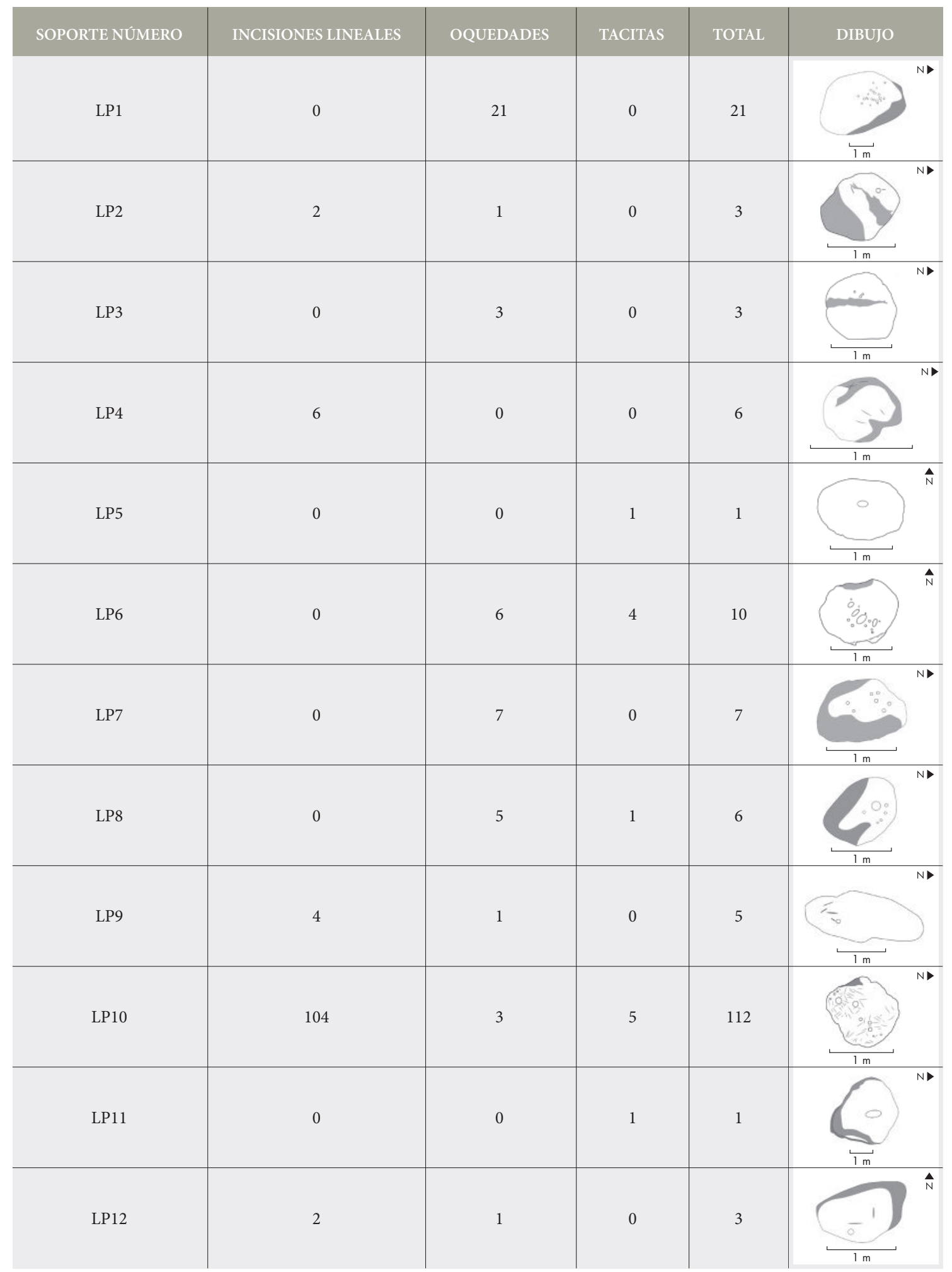




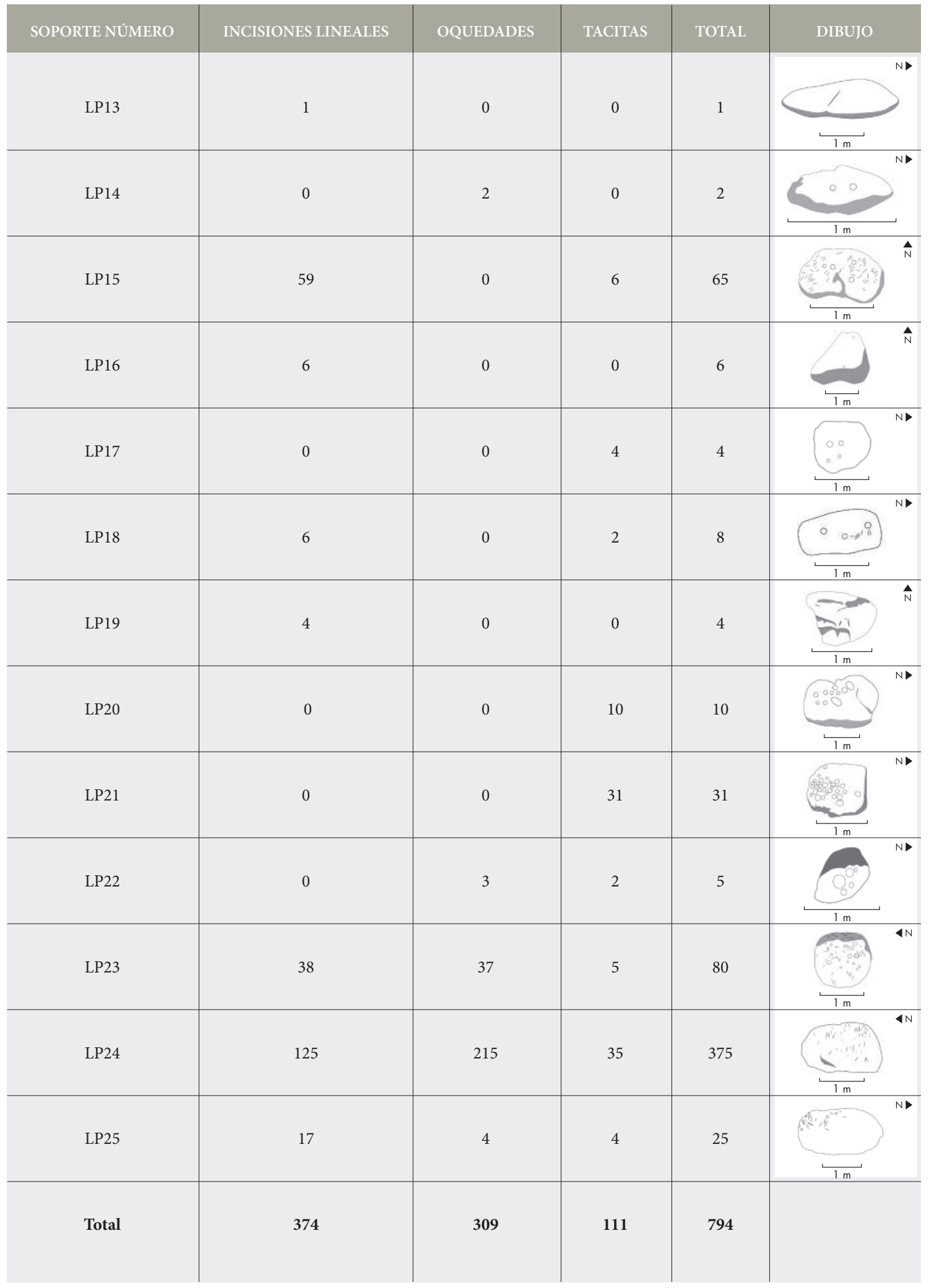



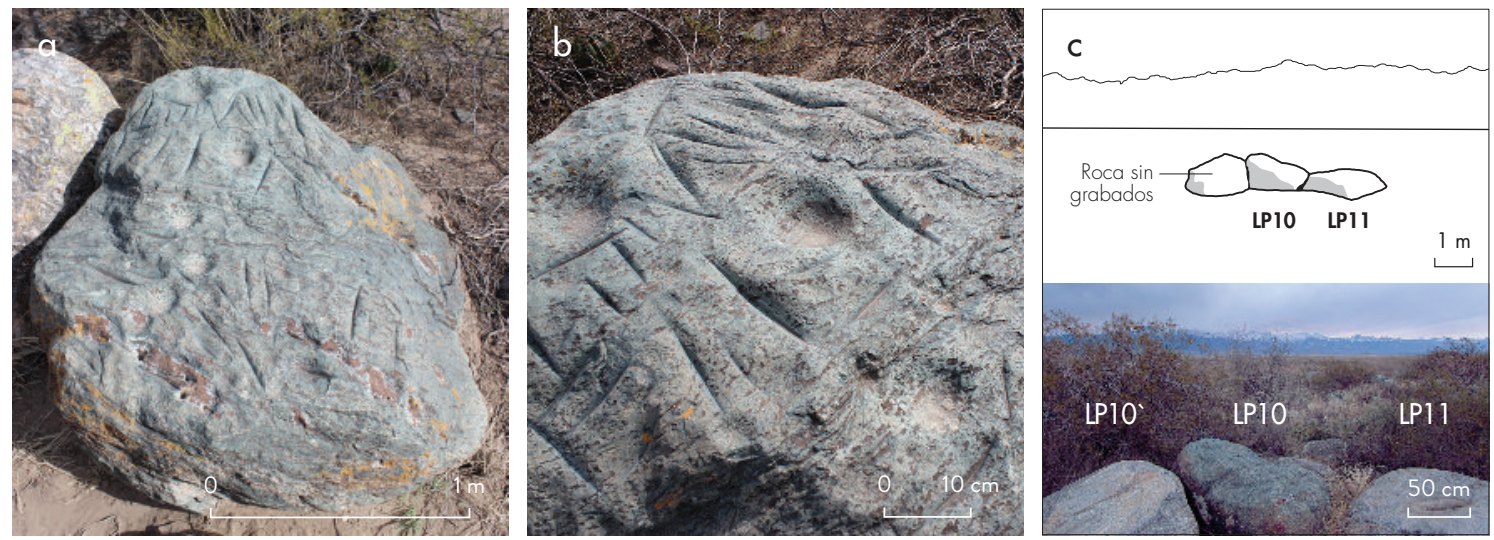

Figura 4. Conjunto LP 10'-LP10 y LP11: a) LP10; b) detalle de grabados de LP10; c) fotografía y esquema del conjunto y la cordillera vistos desde el este. Figure 4. LP 10'-LP10 and LP11 grouping: $\boldsymbol{a})$ LP10; $\boldsymbol{b}$ ) detail of LP10 engravings; $\boldsymbol{c}$ ) drawing and photo of the grouping, facing westward with the mountains in the background.

acabada, excepto el soporte LP8 que contiene un tipo de mortero cupuliforme con una profundidad de $11 \mathrm{~cm}$ y $14 \mathrm{~cm}$ de diámetro. Los grabados ovales son de mayor tamaño y están realizados en solo cuatro soportes (LP5, LP6, LP11, LP20) del total. Las medidas varían entre los 40 y $20 \mathrm{~cm}$ del eje mayor y entre los 18 y $8 \mathrm{~cm}$ del eje menor, y la profundidad entre 15 y $7 \mathrm{~cm}$. Presentan diferentes formas y tamaños con una base irregular donde se observa que un extremo es más profundo que el otro, lo que supone que es la zona donde se ejercía la mayor presión.

Estos tres tipos de grabados (incisiones lineales, oquedades y tacitas) están combinados de distintas maneras en las rocas (tabla 1 y fig. 7). No reconocimos ningún patrón formal en la frecuencia, distribución, orientación o combinación de los distintos tipos de grabados.

Otro tipo menos frecuente de intervención es el canteado de cuatro de las rocas, identificado en el conjunto que forman LP10, LP10' y LP11 y en la roca aislada LP21.

Entre los soportes destacan LP10, LP15, LP23 y LP24 por su mayor tamaño y visibilidad en comparación con el resto de las rocas grabadas, y por la mayor cantidad y variedad de representaciones (fig. 7).

En el sector Oeste, LP10 es una de las rocas con mayor significación por la cantidad y combinaciones de impresiones sobre ella ( $14,1 \%$ de grabados del sitio). La forma es irregular, con la zona de grabados dispuesta en un ángulo de $45^{\circ}$ que asciende de noreste a suroeste. Se registraron 104 incisiones lineales de largos que

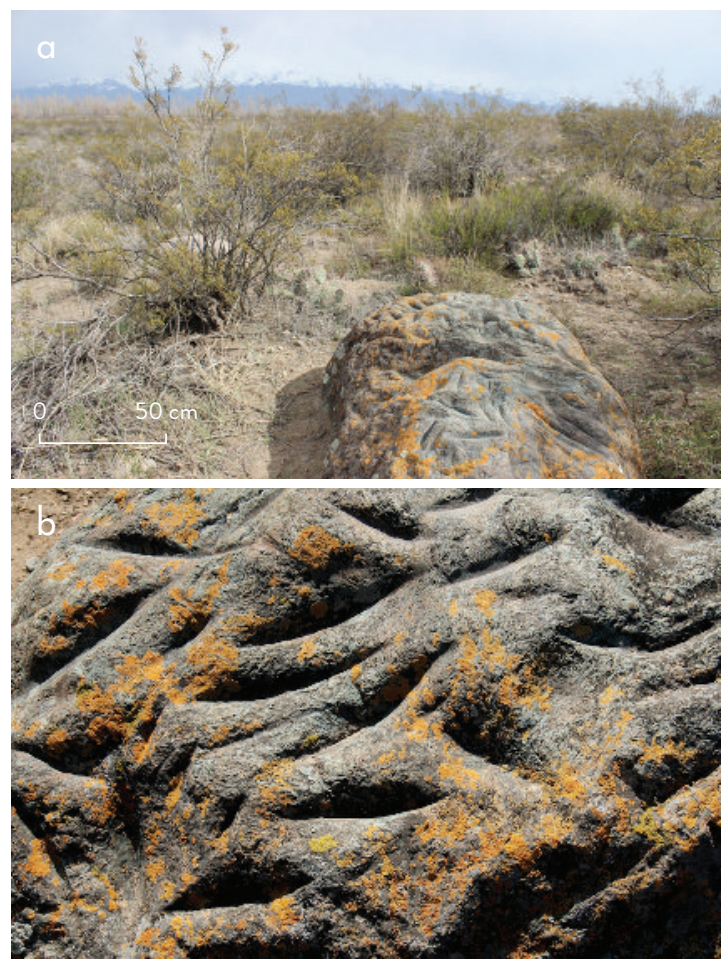

Figura 5: a) soporte LP15; b) detalle de los grabados de LP15. Figure 5: a) LP15 support; $\boldsymbol{b}$ ) detail of engravings on LP15.

varían entre los $2 \mathrm{~cm}$ hasta los $25 \mathrm{~cm}$, en algunos casos presentan superposiciones y en otros se unen formando secciones en V. En cuanto a los otros tipos de grabados, contiene cinco tacitas en una línea descendente en dirección suroeste-noreste. Los tamaños de las tacitas 


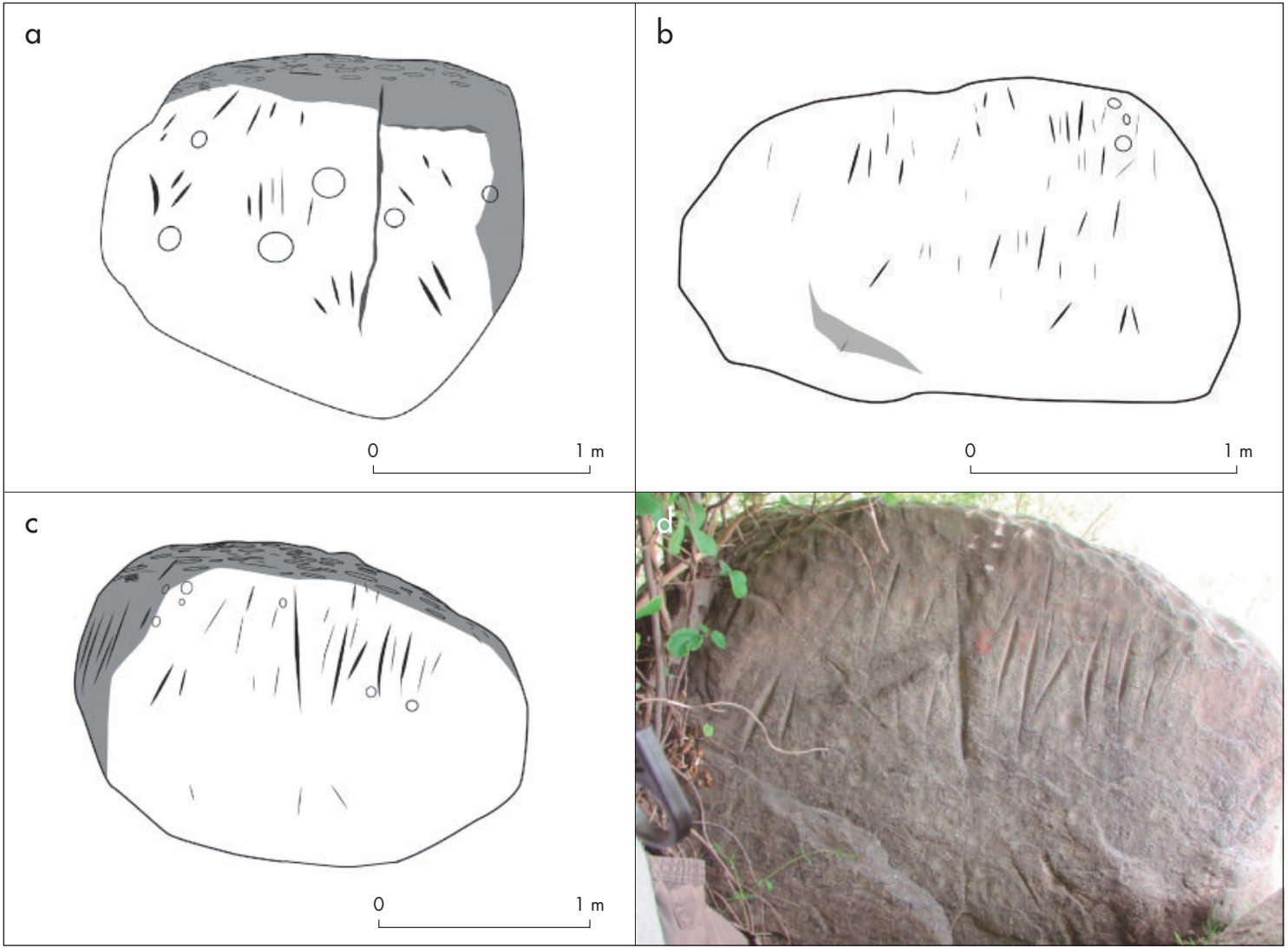

Figura 6. Dibujos de los paneles del soporte LP24: a) panel norte; b) panel oeste; c) panel este; d) fotografía panel este. En gris se destacan los planos y las irregularidades de los soportes. Figure 6. Drawings of LP24 support panels: $\boldsymbol{a})$ north panel; $\boldsymbol{b}$ ) west panel; $\boldsymbol{c}$ ) east panel; $\boldsymbol{d}$ ) photo of east panel. The grey shaded areas indicate the planes and irregularities of the supports.

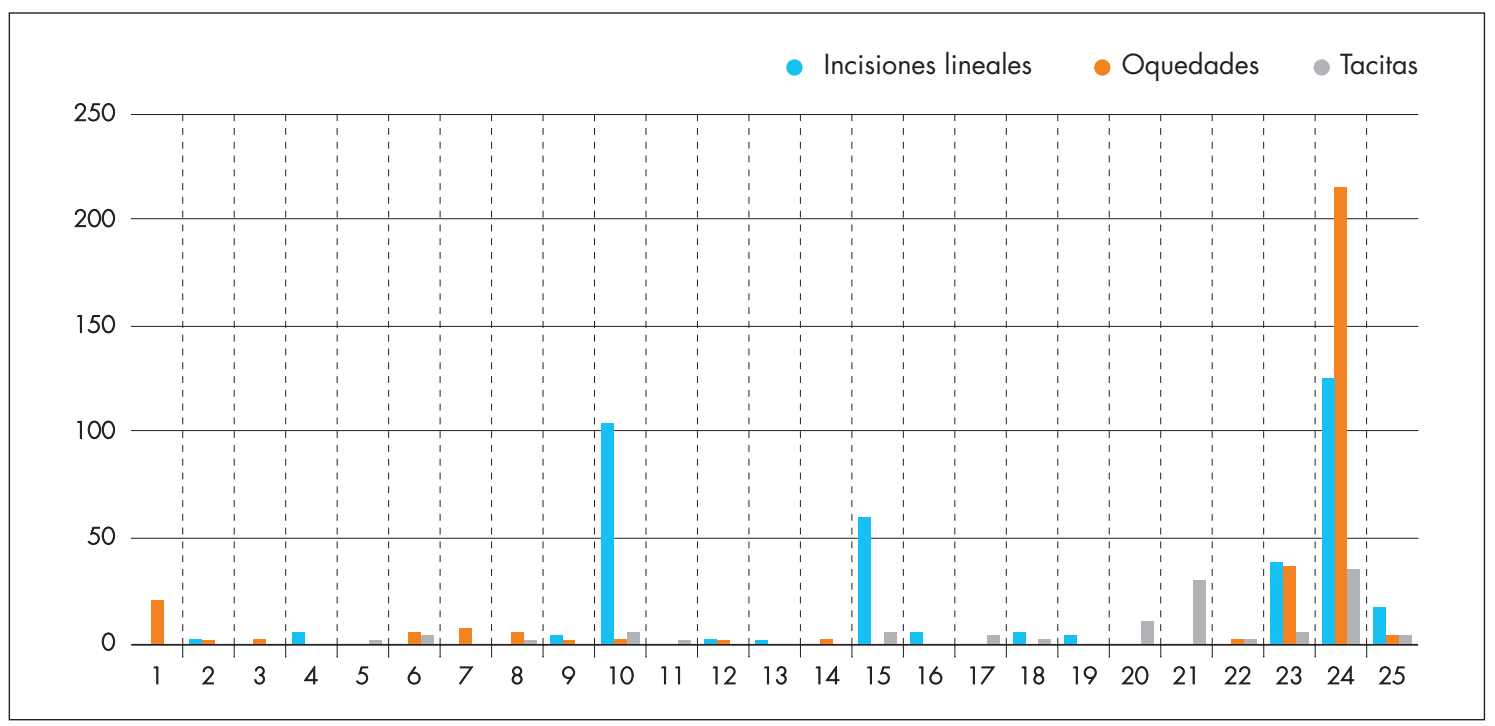

Figura 7. Frecuencia de grabados por soporte y por tipo. Referencias: T: tacitas; O: oquedades; I: incisiones lineales. Figure 7. Frequency of engravings by support and engraving type. T: cups; O: cavities; I: linear incisions. 


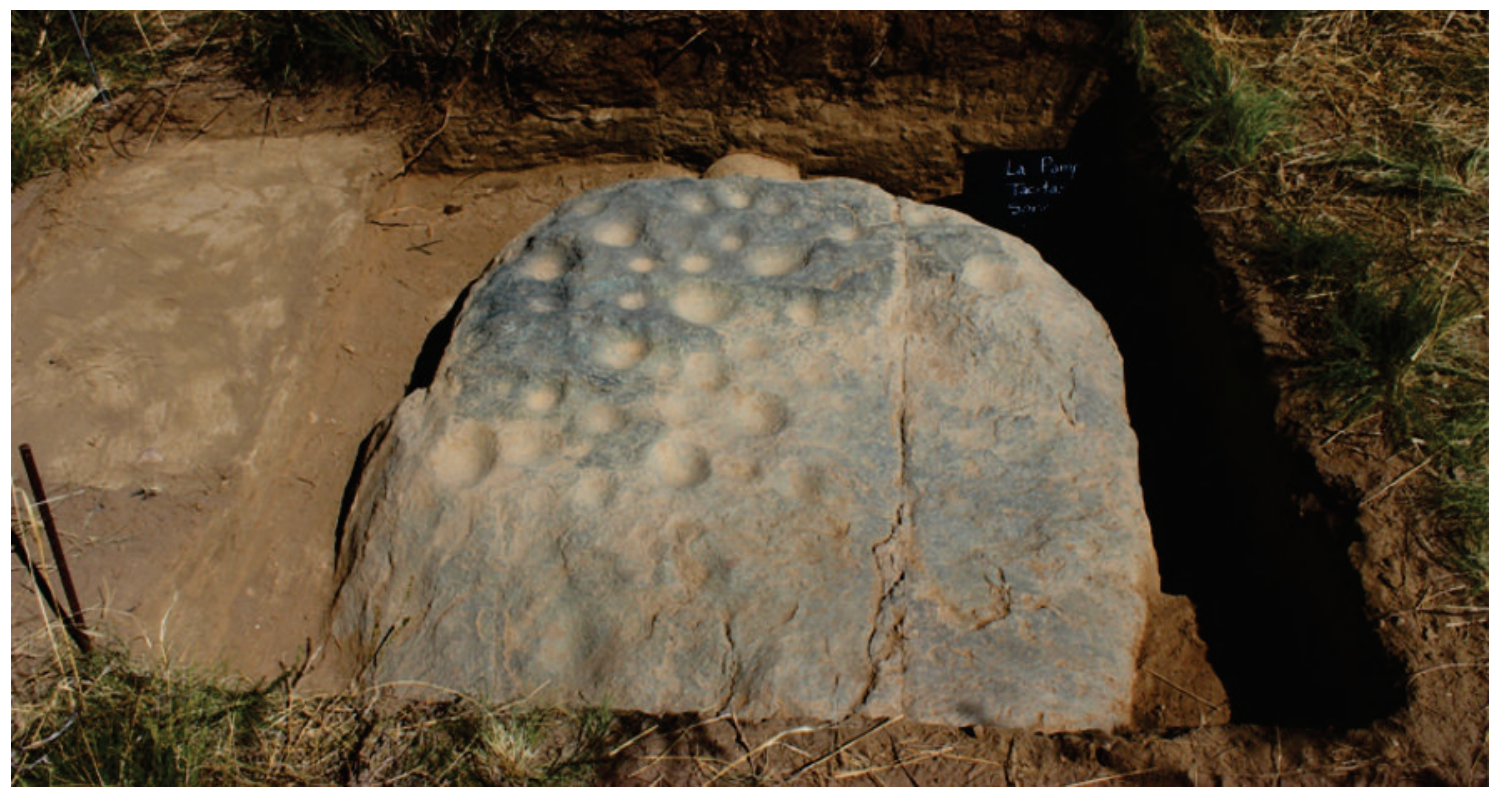

Figura 8. Roca aislada LP21. Figure 8. Solitary rock LP21.

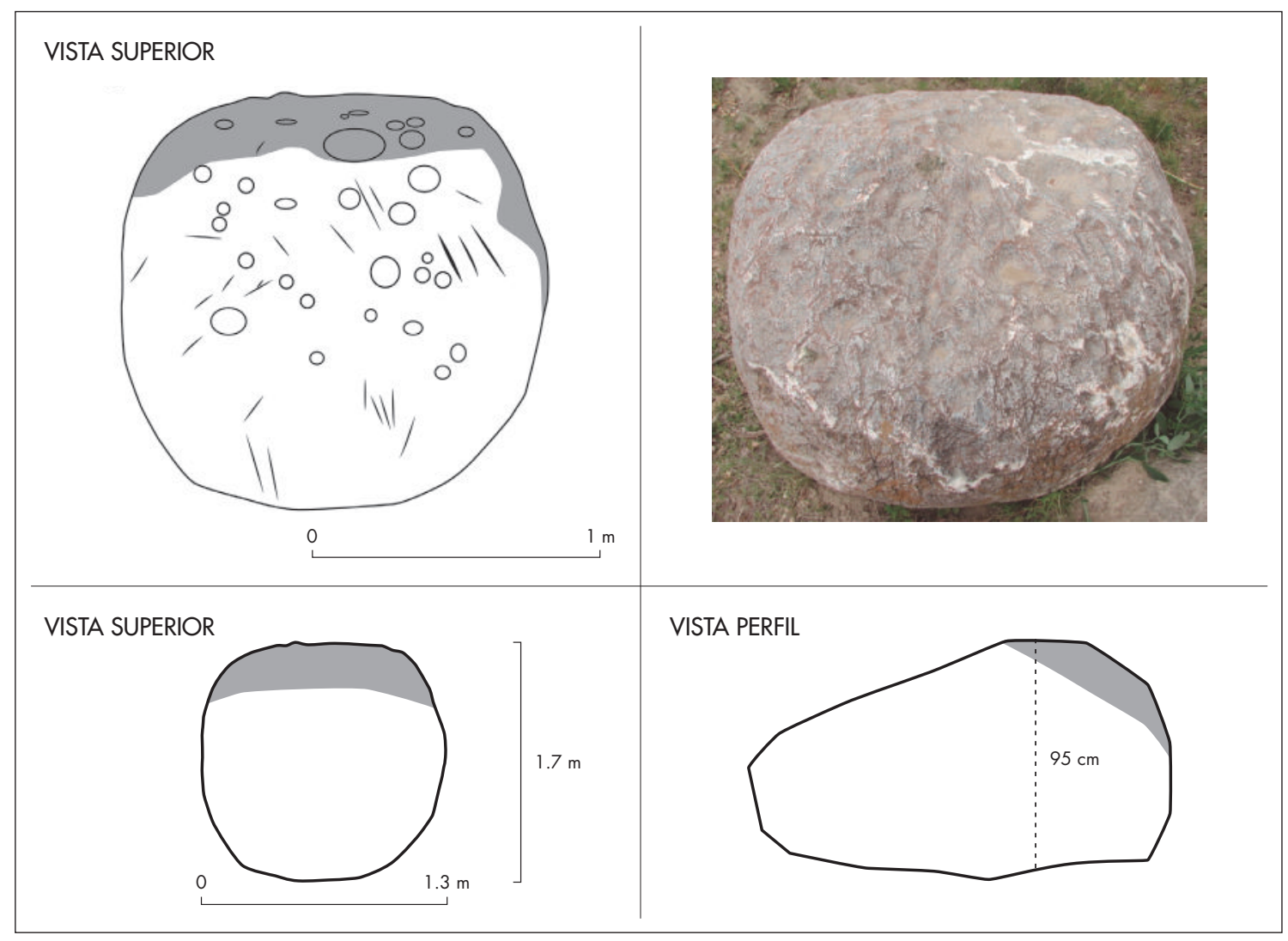

Figura 9. Roca aislada LP23. En gris se destacan los planos y las irregularidades de los soportes. Figure 9. Solitary rock LP23. The shaded grey areas indicate the planes and irregularities of the supports. 
disminuyen de diámetro a medida que descienden en la roca y en el extremo superior suroeste se hallan tres oquedades dispuestas en forma perpendicular a las tacitas (fig. 4a).

El soporte LP15 tiene superficie irregular redondeada, cuya cara superior se dispone en un ángulo que va en descenso con orientación oeste-este (figs. 5a y b). Cuenta con dos tipos de grabados ( $8,2 \%$ del sitio), seis tacitas entre 8 y $11 \mathrm{~cm}$ de diámetro y 59 incisiones lineales con un promedio de $12,5 \mathrm{~cm}$ de largo que se disponen por toda la roca en múltiples direcciones sin un patrón definido. Estas son mucho más profundas que las de LP10 y alcanzan hasta 2,5 cm (fig. 5b).

El soporte LP21 fue descubierto en excavación, ya que los grabados más sobresalientes se encontraban al nivel de piso actual. En la cara superior horizontal, 31 tacitas fueron grabadas $(27,9 \%$ de esa categoría), las cuales se concentran en el sector sureste de la roca. El soporte tiene una forma cuadrada bastante regular, lo que hace pensar en la posibilidad de que haya sido canteado (fig. 8).

LP23 y LP24 se encuentran en el extremo este del sitio y destacan por la cantidad de intervenciones que presentan. LP23 (10,1\% de grabados del sitio) se halla desplazada de la posición original por la construcción de un sendero moderno y presenta una forma semiesférica con grabados distribuidos en todo el soporte. Exhibe los tres tipos de grabados ( 5 tacitas, 37 oquedades, 38 incisiones lineales) distribuidos aleatoriamente sin un patrón de orientación o posición (fig. 9).

LP24 contiene la mayor cantidad de grabados de todo el sitio (47,2\%), y también se encuentran representados los tres tipos de intervenciones. El soporte tiene cinco caras/paneles grabados, uno superior y cuatro laterales (fig. 6). La cara superior contiene los tres tipos de grabados con la mayor concentración de oquedades (215), incisiones lineales (23) y tacitas (29). La cara lateral norte desciende desde la cara superior en un ángulo de $45^{\circ}$ aproximadamente de sur a norte y contiene incisiones lineales (22) combinadas con tacitas (6) (fig. 6a). El resto de las caras laterales presentan en su mayoría incisiones con profundidades y longitudes muy superiores al resto de los soportes. En la cara lateral oeste estas tienen longitudes y profundidades menores (fig. 6b). La cara sur tiene incisiones más profundas que alcanzan los $3,9 \mathrm{~cm}$ y una longitud de $56 \mathrm{~cm}$, mientras que la cara este tiene una incisión que alcanza los 47 $\mathrm{cm}$ de longitud y $3 \mathrm{~cm}$ de profundidad (figs. $6 \mathrm{c} \mathrm{y} \mathrm{d}$ ).
Las rocas LP23 y LP24 presentan grabados distribuidos en todas sus caras, a diferencia del resto de los soportes que concentran las intervenciones en su cara superior horizontal. Particularmente, el soporte LP24 tiene, además de la mayor frecuencia de grabados, unas medidas superiores al resto de los soportes con una superficie de 3,30 $\mathrm{m}^{2}$ y una altura que alcanza los 1,25 m.

\section{Segunda escala: análisis del sitio}

El sitio La Pampa se localiza en el sector pedemontano de la microrregión. Tiene una orientación longitudinal oeste-este, que sigue la dirección del Río de las Tunas (figs. 1 y 2). Los cauces del río demarcan los límites naturales de la distribución de rocas en el sitio: el cauce activo actual al norte, y otro cauce inactivo al sur (fig. 3). Las rocas se localizan en la encrucijada de dos caminos actuales: la ruta provincial 89 (dirección noreste-suroeste) y la calle La Pampa (dirección este-oeste). El sitio tiene una superficie plana, con pendiente de entre $2^{\circ}$ y $10^{\circ}$. La vegetación se caracteriza por matorrales de Larrea divaricata y Piptochaetium napostaense y cactáceas.

Las rocas con grabados están distribuidas en una superficie de 24,8 ha. Algunas se encuentran concentradas y otras dispersas, por lo cual, con un criterio operativo para realizar análisis de distribución espacial, distinguimos dos sectores de concentración denominados Sector Oeste y Sector Este (fig. 3). A su vez, dentro de cada uno de estos sectores, distinguimos concentraciones a partir de las distancias entre diferentes grupos de rocas: cada concentración está compuesta por dos o más rocas ubicadas a una distancia no mayor a $50 \mathrm{~m}$, en tanto que las que se encuentran a mayor distancia se consideran "rocas aisladas". Estas últimas son LP16, LP20, LP21, LP22 y LP23. Distinguimos cuatro concentraciones denominadas, de oeste a este, C1, C2 y C3 en el Sector Oeste y C4 en el Sector Este (fig. 3).

C1 está formada por 4 rocas (LP1, LP2, LP3 y LP4), dos de las cuales se localizan sobre la margen del paleocauce. Este conjunto demarca el límite oeste del sitio.

C2 se ubica también sobre el paleocauce, a unos 90 $\mathrm{m}$ de distancia de $\mathrm{C} 1$ en dirección sur-este. Concentra la mayor cantidad de rocas intervenidas (LP5, LP6, LP7, LP8, LP9, LP10' LP10, LP11, LP12, LP13, LP14, LP15. Fig. $10)$, y la mayor variedad de combinaciones de grabados (Rocha 2017a). En este conjunto, la disposición de las rocas grabadas tiene forma circular. Otras rocas próximas, que no contribuyen a esta disposición espacial, se 


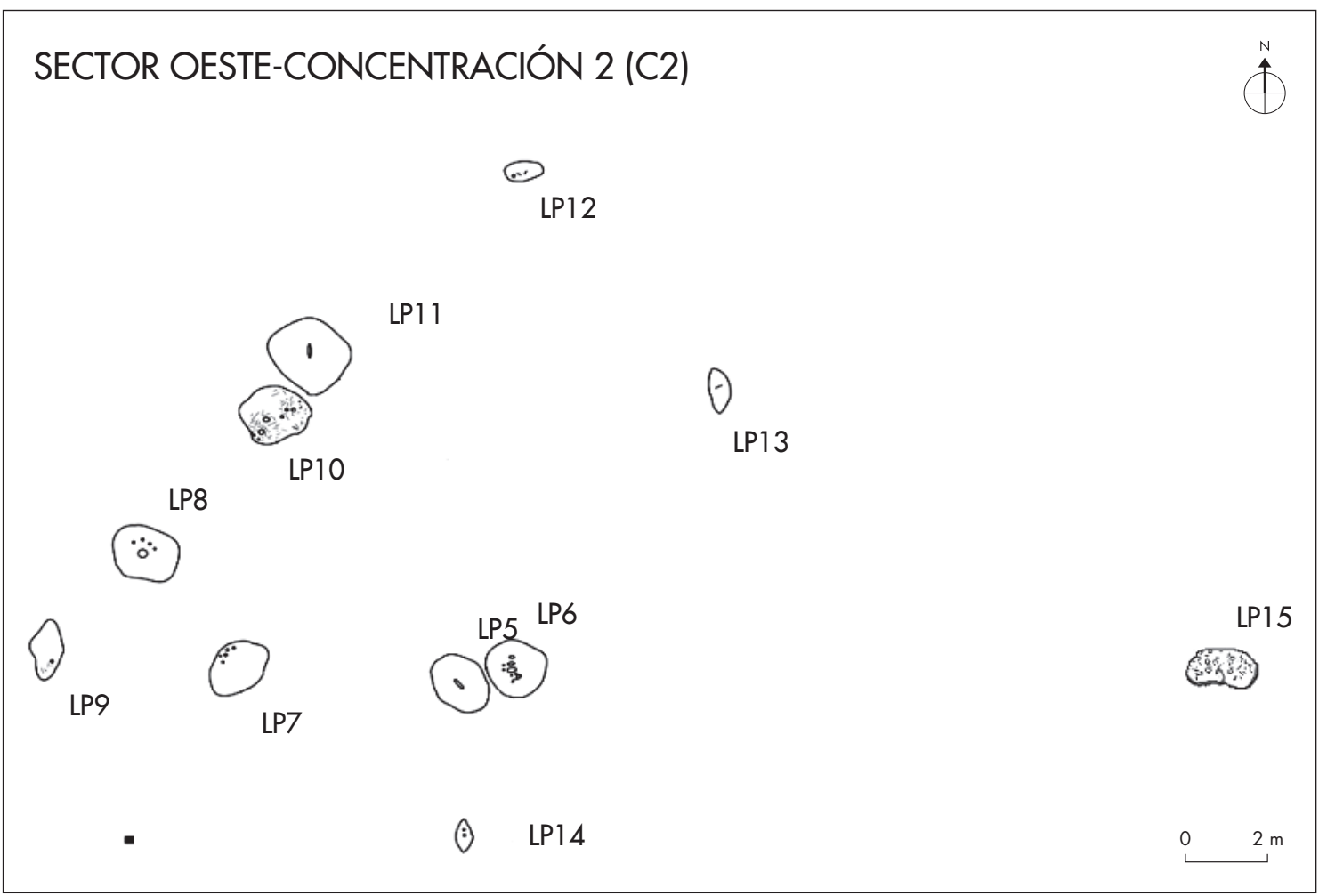

Figura 10. Distribución espacial de soportes en la concentración 2 (C2). Figure 10. Spatial distribution of supports in concentration 2 (C2).

desestimaron como soportes para realizar grabados. Los soportes LP10 y LP11, junto con una roca canteada sin grabados, que denominamos LP10', asemejan un panel con gran cantidad y variedad de intervenciones (tabla 1 y fig. 4). De sur a norte, LP10' y LP10 presentan dos lados canteados rectos enfrentados y separados entre sí por $15 \mathrm{~cm}$ de distancia. El conjunto se completa con la roca LP11, con una tacita ovalada y el lado este canteado para formar una superficie de apoyo. Desde una perspectiva este-oeste las tres rocas asociadas tienen de fondo la cordillera Frontal con picos de más de $5000 \mathrm{~m}$ de altura y se presenta como una escena que impacta visualmente (fig. 4c). Enfrentados en dirección oesteeste, los soportes LP5 y LP6, asociados espacialmente, tienen tacitas ovales. Un conjunto de rocas dispuestas en el extremo oeste de este sector tienen una posición alineada en dirección noreste-suroeste (LP8, LP9, LP10, LP10, LP11 y LP12). La organización espacial de las rocas proyecta puntos de fuga y ejes hacia los cuatro puntos cardinales.

C3 está integrada por las rocas LP17, LP18 y LP19. Se localiza a unos $80 \mathrm{~m}$ de distancia de C2, en dirección noreste. De este modo, las tres concentraciones descritas se proyectan hacia tres puntos cardinales: oeste (C1), sur (C2) y este (C3). La roca aislada LP16, ubicada a $80 \mathrm{~m}$ al norte de $\mathrm{C} 2$, marcaría el extremo norte del conjunto.

El resto de las rocas (LP20 a LP25) se localizan en una proyección hacia el este de los conjuntos principales, lo que fortalece la direccionalidad oeste-este de estos conjuntos. LP20 está a $120 \mathrm{~m}$ de distancia de C2 y a 60 $\mathrm{m}$ de C3; en tanto que LP21 se ubica a $500 \mathrm{~m}$ de C2. En ambas solo se grabaron tacitas (fig. 8). Desde LP21 a una distancia de $250 \mathrm{~m}$ aproximadamente rumbo noreste se encuentra LP22, junto al cauce activo del Río de las Tunas. Esta roca fue desplazada en tareas de limpieza de los terrenos de cultivo, por lo que su localización actual rompe la direccionalidad oeste-este en la que se ubica el resto de los soportes. El soporte LP23 se emplaza a $600 \mathrm{~m}$ respecto a LP22. A $68 \mathrm{~m}$ hacia el este de LP23 encontramos la última concentración, C4, que agrupa a LP24 y LP25. Estos soportes se encuentran alineados en dirección oeste-este y son los más relevantes del sitio, por tener la mayor superficie grabada y la mayor concentración de representaciones (tabla 1, fig. 7). 


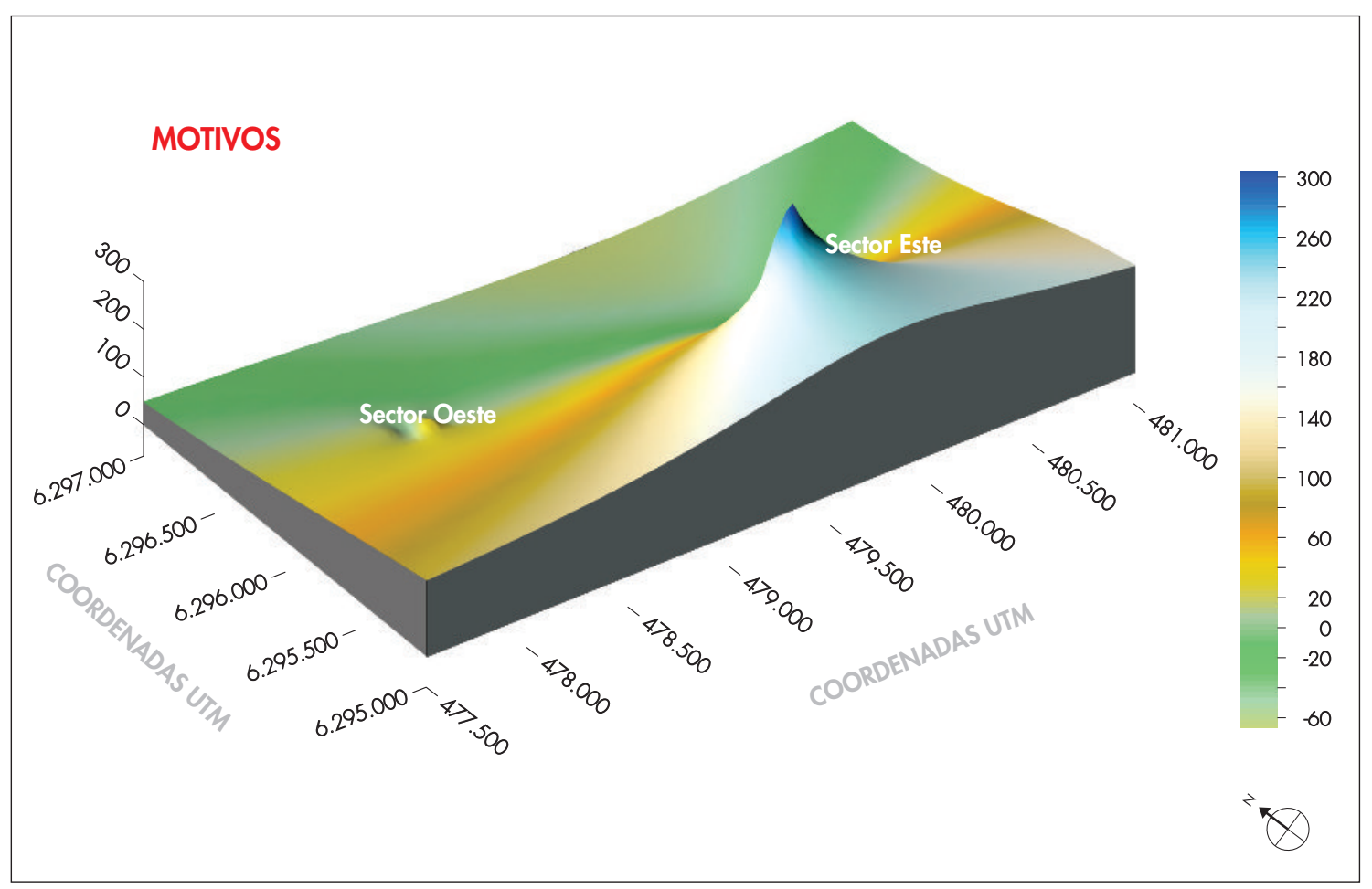

Figura 11. Interpolación kriging de grabados rupestres del sitio la Pampa. Figure 11. Kriging interpolation of the rock engravings at the La Pampa site.

Se generó un estadístico geoespacial de interpolación kriging con la distribución de motivos grabados del sitio, a partir del cual se desarrollaron representaciones 3D con una capa de datos del total de los motivos (fig. 11) y otras tres con las categorías de incisiones, oquedades y tacitas (fig. 12). La imagen ráster resultante refleja los sectores Oeste, el cual presenta el 35,01\% de los motivos, y Este con el 60,45\%.

La discriminación por categoría de motivos identifica una intensidad mayor de la cantidad de incisiones lineales en torno a LP24 (33,4\% de las incisiones), LP23 (10,16 $\%)$ y LP25 (4,6\%) reflejada en un pico de la variable en el Sector Este, en la derecha de la figura 12a. El Sector Oeste concentra una influencia de menor importancia alrededor de LP10 (27,8\% de las incisiones) y LP15 $(15,8 \%)$. Las oquedades muestran una distribución espacial similar a la anterior, aunque con valores $\mathrm{Z}$ un poco menores y más desequilibrada en favor del Sector Este. Las rocas LP24 (69,6\%) y LP23 (12\%) vuelven a representar un pico notable de intensidad de la variable, mientras que el Sector Oeste concentra una pequeña concentración en LP1 (6,8\%) (fig. 12b). Finalmente, la categoría de las tacitas muestra picos más suavizados y atenuados debido a que representa la frecuencia de menor importancia estadística. Nuevamente se destaca, relativamente, el Sector Este con LP24 (31,5\% de las tacitas), seguido por el Sector Oeste (LP20, 9\%). Sin embargo, la roca aislada LP21 representa una superficie suavizada realzada que concentra el 27,2\% (fig. 12c).

Con el propósito de contextualizar los grabados realizamos excavaciones en el Sector Oeste, donde se encuentra la mayor concentración de artefactos en superficie $\mathrm{y}$ de rocas intervenidas (no encontramos materiales en superficie en el Sector Este). Trece cuadrículas de $1 \mathrm{~m}^{2}$ fueron excavadas mediante niveles artificiales de $5 \mathrm{~cm}$ de profundidad, ya que no se identificaron diferencias estratigráficas. Se alcanzaron profundidades de entre 30 y $40 \mathrm{~cm}$ hasta las que se reconocieron niveles de ocupación, y debajo de los cuales se encontró roca.

Diez cuadrículas se localizaron en C2, en torno a las rocas que presentaban mayor actividad cultural, como LP10/LP11 (sondeos 2, 4 y 5) y LP5/LP6 (sondeos 6 y 7) y en la zona libre entre el conjunto de rocas de este sector (sondeos 1, 3, 8, 9 y 10) (fig. 13). Otros tres 


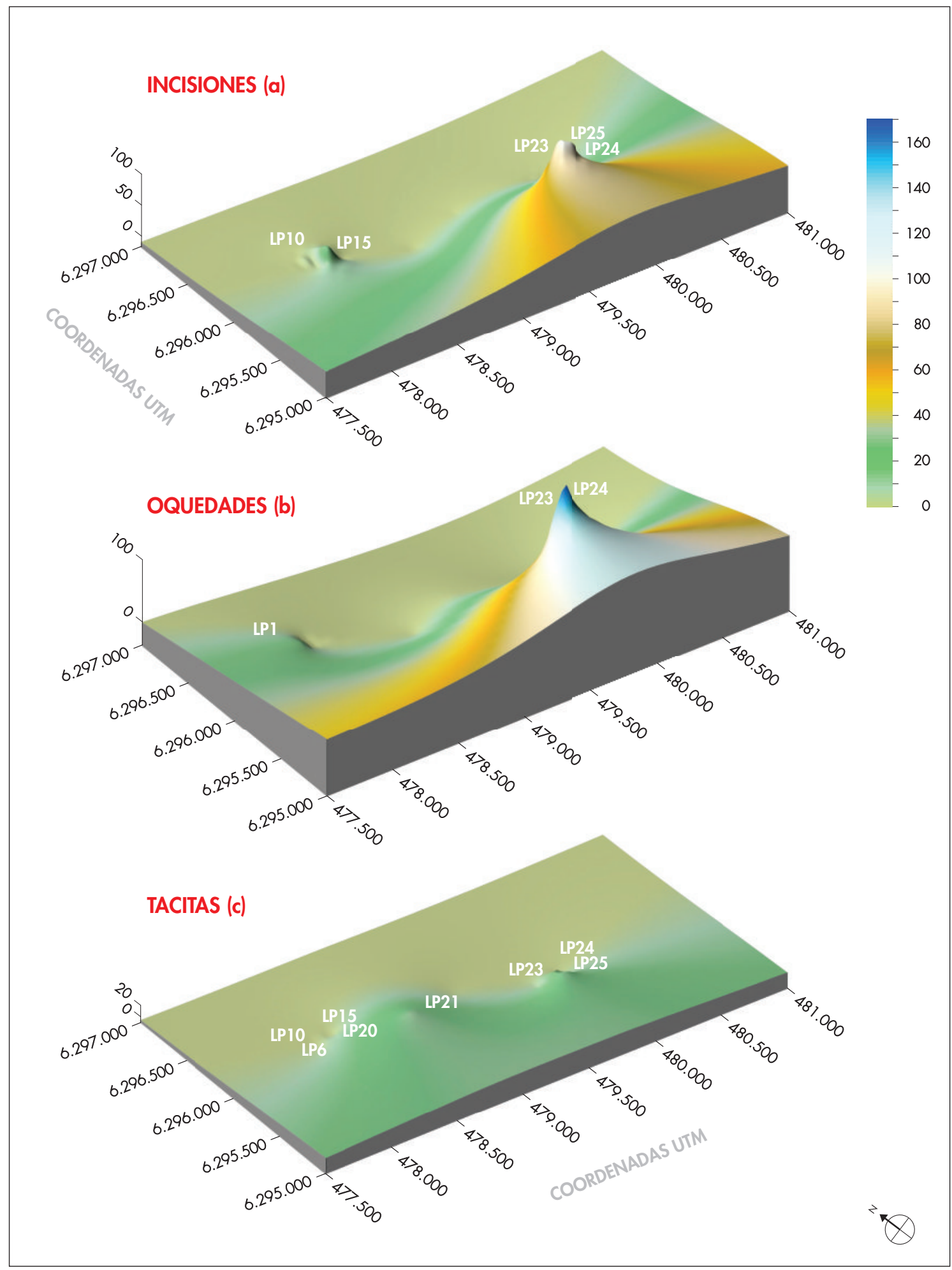

Figura 12. Interpolación kriging por categorías de motivos grabados en La Pampa: incisiones (a), oquedades (b) y tacitas (c). Figure 12. Kriging interpolation of motif categories at the La Pampa site: incisions (a), cavities (b) and cups (c). 


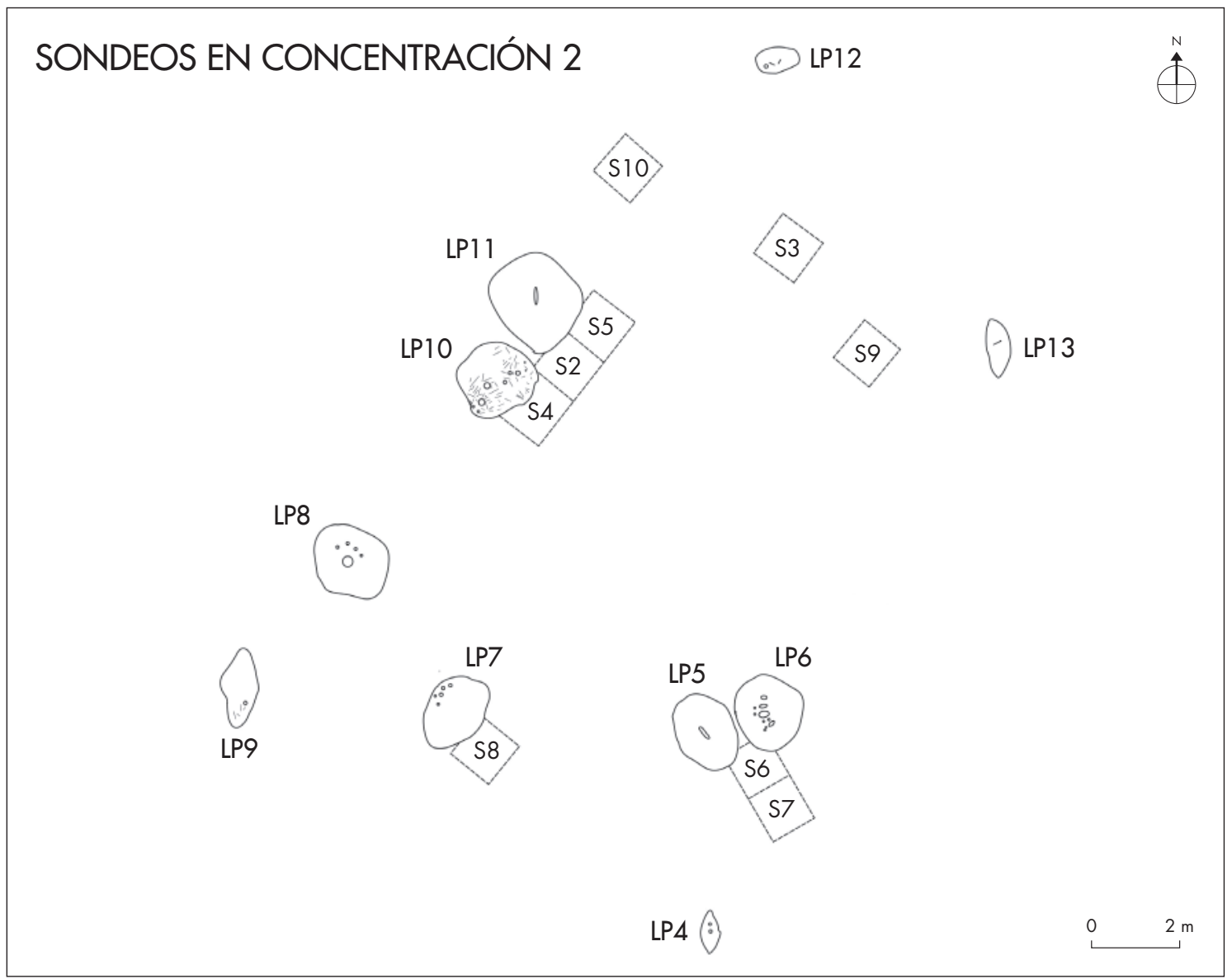

Figura 13. Plano de distribución de sondeos en la concentración 2 (C2) del Sector Oeste. Figure 13. Distribution of test pits performed at concentration 2 (C2) in the Western Sector.

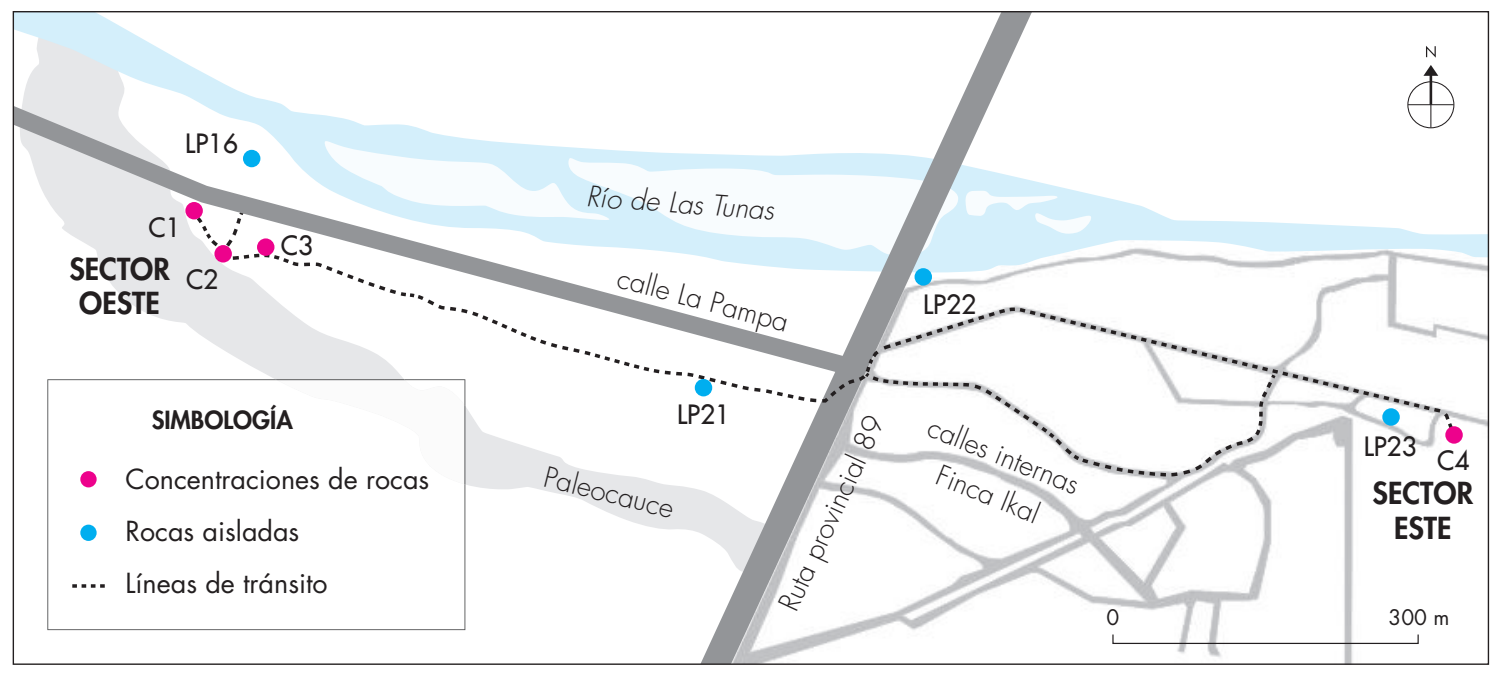

Figura 14. Mapa de tránsito, con indicación de los senderos y caminos actuales. Figure 14. Map of transit routes, with present-day trails and roads included. 
sondeos nos permitieron descubrir la roca LP21 (fig. 8). No se encontraron restos orgánicos (botánicos o faunísticos), solo cerámicos y líticos.

Se registraron 44 fragmentos cerámicos (NMv= 44). El conjunto es tecnológica y tipológicamente homogéneo: pastas en distintos matices de marrón (muy baja frecuencia de grises, $\mathrm{N}=3$ ) y superficies alisadas. Algunos tiestos presentan decoración incisa con chevrones $(\mathrm{N}=5)$ e imbricada $(\mathrm{N}=1)$, característica del componente cerámico Agrelo (Canals Frau 1956), fechado en proximidades de este sitio entre los siglos v y xIv DC (Ots et al. 2016).

Los fragmentos de pucos y de ollas o jarras indican que serían de tamaños pequeños (aproximadamente 14 $\mathrm{cm}$ de diámetro de borde, $8 \mathrm{~cm}$ de diámetro de base). Ninguno de los tiestos tiene señales de termoalteración, por lo que suponemos la asociación de esta cerámica con actividades de servicio y consumo de alimentos y bebidas.

El conjunto lítico está compuesto por desechos de talla, un núcleo, percutores, un artefacto de molienda (mano fragmentada) y una roca horadada. La mayoría de los desechos son lascas primarias y secundarias $(\mathrm{N}=78)$ con filos naturales y sin rastros de formatización, el 95\% de las cuales se realizó sobre rocas basálticas. Los percutores $(\mathrm{N}=4)$ se hicieron sobre rocas ígneas. Son cantos rodados acondicionados, con un extremo potencialmente activo con astillado irregular producido por las marcas de percusión y otro pasivo.

Al comparar el tipo de roca de los soportes con los desechos líticos y las herramientas (percutores) se observa que estas últimas tienen una dureza superior a la de las rocas intervenidas, en una razonable correlación de durezas entre los bloques intervenidos y los materiales líticos que aparentemente fueron utilizados para la intervención.

El análisis de tránsito se realizó a partir de la demarcación de las principales líneas de accesibilidad entre los conjuntos de soportes. Se marcaron con GPS los senderos existentes en el terreno que tuvieran un acceso reconocible. Se comprobó que las rutas están orientadas por un punto de interconexión oeste-este entre los sectores de mayor significación (fig. 14). La ruta comienza desde $\mathrm{C} 1$ y continúa en dirección oestesureste hacia C2; desde aquí surge un sendero hacia el norte que conduce a la roca más extrema en sentido norte (LP16) cercana a un brazo activo del Río de las Tunas. También desde $\mathrm{C} 2$ y hacia el este surge un desvío noreste que se interconecta con C3. Desde C3 sigue un sendero de $70 \mathrm{~m}$ aproximadamente que conecta con la roca LP20 y a unos $250 \mathrm{~m}$ llega a la roca LP21. En este punto se observa que hay una continuidad del sendero hacia el este hasta LP 22, 23, 24 y 25 (fig. 14).

Cada sector se encuentra en una declinación de $10^{\circ}$ aproximadamente, con una altura que va en descenso de oeste a este y que costea los brazos del Río de las Tunas. El tránsito sigue la dirección de los cauces de agua y remarca una zona que se encuentra rodeada y limitada por dichos cauces. En el Sector Oeste se destaca una simetría en las distancias entre los conjuntos $\mathrm{C} 1$, C2 y C3, pero a partir de LP20 y LP21 los soportes se alejan, por lo que esa simetría se rompe.

Para el análisis de visibilidad se tomaron dos puntos de referencia: el centro de la concentración 2 (C2) y la roca aislada LP21. Se observó que no hay intervisibilidad entre ambos puntos y que el alcance visual se encuentra limitado a un espacio contiguo, debido a que la vegetación y las rocas sin intervención dificultan el alcance visual. La altura actual de los soportes, alrededor de $40 \mathrm{~cm}$ más bajos que en los niveles arqueológicos, y la escasa pendiente del terreno no permiten que estos sean identificados desde los puntos de accesibilidad actuales más cercanos (la calle La Pampa y la ruta 89).

\section{Tercera escala: la microrregión, cuenca del Río de las Tunas}

La investigación a escala microrregional se realizó mediante la prospección pedestre sistemática e intensiva de un área discreta de $600 \mathrm{~km}^{2}$ en la cuenca del Río de las Tunas (Ots 2005, 2007). De acuerdo con las propuestas de la ecología del paisaje (Forman \& Godron 1986), consideramos el río como un corredor que conecta y comunica distintos ambientes, en este caso, la cordillera (5000-1700 msnm) y el oasis pedemontano (1700-700 $\mathrm{msnm}$ ). En las proximidades de este río y de sus afluentes (arroyos Santa Clara, Los Tábanos-Mortero, del Novillo Muerto, San Pablo, Las Rosas, Villegas y Agua Amarga) hemos localizado asentamientos estacionales en el sector cordillerano y de ocupación permanente (aldeas) en el sector pedemontano, datados en ca. 1500-400 años AP. En ellos se reconocen múltiples funciones asociadas con actividades domésticas y de subsistencia (entre otros, Ots 2005, Ots et al. 2011, 2016) (localización de los sitios en figura 2).

En los sitios que se encuentran en el borde del sector cordillerano hasta los 1650 es frecuente encontrar 
rocas con morteros, conanas y manos de moler. En uno de ellos, en la terraza del Arroyo Las Rosas, dos rocas aisladas presentan grabados similares a los de La Pampa (tacitas y hoyuelos) (Ots 2005). El más relevante de estos sitios cordilleranos, por el tamaño y forma de la roca y la cantidad y tamaño de las cavidades $(\mathrm{N}=3)$, es Arroyo del Novillo Muerto. En este caso, el análisis de los microrrestos rescatados de las tacitas cupuliformes (Schinus sp., Prosopis sp., Larrea sp.), sumado al resto del registro arqueológico, nos sugiere para estas concavidades profundas la funcionalidad del procesamiento de vegetales, aunque no pueden descartarse otras funciones (Ots et al. 2016).

La distribución de rocas con morteros y otros artefactos de molienda en las proximidades de los cursos de agua se puede interpretar en relación con la explotación económica de los recursos de recolección disponibles en el piedemonte y la cordillera (Ots 2007, Ots et al. 2016). Este patrón está asociado a las ocupaciones estacionales del Período Alfarero Medio.

A pesar de la proximidad de La Pampa a sitios pedemontanos multicomponentes, con reocupación tardía-inca, como Agua Amarga o Puesto La Isla (distantes 1,5 y $6 \mathrm{~km}$ del sitio, respectivamente), no encontramos restos que indiquen que haya sido reocupado durante esta etapa. Tampoco se registraron representaciones que puedan asignarse al Tardío-inca, como en otros casos regionales (v.g. Tunduqueral en el Valle de Uspallata. Schobinger 2009). Este dato acota el rango de ocupación y producción de las representaciones.

Desde el sitio, localizado en un sector transicional entre las ocupaciones del sector cordillerano y del oasis pedemontano, se logra el control visual directo hacia áreas muy específicas: la cordillera al oeste y la planicie al este; en el primer caso debido a su monumentalidad, y en el caso de la planicie la visibilidad es plena debido a la diferencia altitudinal con respecto a este sector (aproximadamente $500 \mathrm{~m}$ ).

La composición cartográfica general de la figura 15 muestra la visibilidad desde la concentración C2 hacia el oeste. Las celdas de color en la figura son los espacios visibles desde el sitio. La transparencia de capa muestra un ráster de sombreado bajo el ráster de elevación e incorpora la salida procedente de un análisis de cuenca visual que representa la relación entre visibilidad y terreno. Observamos que, desde La Pampa, la cordillera es ampliamente visible. Se muestra el resultado de cuenca visual (total de superficie visible

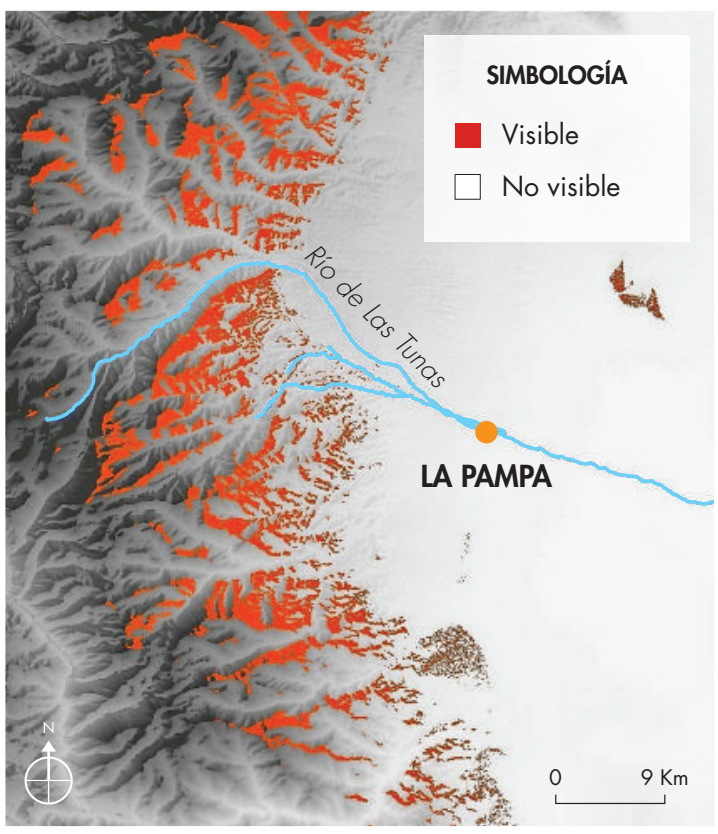

Figura 15. Mapa de visibilidad desde C2 hacia el oeste. Figure 15. Map indicating visibility from C2, looking west.

desde un punto) y también de la intervisibilidad con los otros sitios (fig. 2). Las pruebas aplicadas permiten establecer una correlación entre la ubicación topográfica y el grado de visibilidad. En el detalle de la figura 2 se observa que no hay visibilidad desde los otros sitios de la microrregión hacia La Pampa, ni desde La Pampa hacia los otros sitios.

\section{DISCUSIÓN}

Al integrar las distintas escalas de análisis (los soportes grabados, el sitio y la microrregión) podemos proponer la discusión de algunas interpretaciones sobre los grabados del sitio La Pampa.

Los antecedentes de estudios sobre representaciones rupestres han destacado que, en algunos casos, estas suelen encontrarse en relación con rutas que conectan distintos elementos del paisaje y en sectores donde estas se cruzan (v.g. Bradley et al. 1999). En esos casos, los sitios se encuentran, como en La Pampa, relacionados con poblaciones con un patrón móvil de explotación de recursos, en sectores del paisaje asociados con ese tipo de movilidad, con las rutas tradicionales de trashumancia y con la demarcación de esos recursos (Bradley 
et al. 1994, Troncoso 2008). Las bases residenciales y los asentamientos estacionales se localizan en otros sectores del paisaje, en tanto que puntos significativos son "marcados" con las representaciones rupestres. Otro aspecto significativo de su localización es la visibilidad directa hacia áreas específicas.

Los grabados rupestres del Río de las Tunas están asociados a poblaciones con movilidad residencial, con ocupaciones permanentes en el sector pedemontano y estacionales en la cordillera, que definimos como sociedades de pequeña escala. Los asentamientos se identifican por concentraciones de materiales en superficie, ya que las construcciones residenciales eran de material perecedero, por lo que las rocas grabadas de La Pampa son las únicas estructuras visibles que se conservan de estas ocupaciones en la microrregión.

El Río de Las Tunas es el corredor que conectaba los sitios estacionales de molienda, las rocas aisladas con grabados, las bases residenciales y el conjunto de grabados de La Pampa. El sitio es un marcador que se encuentra en el cruce de dos vías de tránsito, una que se dirige hacia la cordillera (donde se encuentran las nacientes del Río de Las Tunas y el volcán Tupungato, $6570 \mathrm{msnm}$ ) y otra que conecta esta microrregión con otros sectores de ocupación indígena en el Valle de Uco (v.g. El Manzano y el paso del Portillo de Piuquenes que comunica con el valle de Aconcagua).

Este sitio se localiza en un espacio transicional entre el ambiente cordillerano y el oasis pedemontano (Rocha 2017), y si bien la visibilidad del espacio inmediato es reducida, desde allí se ejerce un control visual tanto de la cordillera como de la planicie hasta unos $25 \mathrm{~km}$ de distancia. El sitio tiene una direccionalidad oeste-este; desde él se dominan áreas de recursos diferenciados hacia ambas direcciones: para caza y recolección hacia el oeste, complementados con la producción de alimentos hacia el este (Ots et al. 2016).

La distribución espacial de las rocas manifiesta una organización del paisaje, una determinada "arquitectura" (Criado Boado 1999: 35) que la distingue de otro tipo de sitios del área, y que en el caso de La Pampa parece estar estructurada por la concentración C2. Si bien el mayor número de representaciones se encuentran en C4, en C2 es donde se da la mayor acumulación de rocas que tienen intervenciones complejas (combinación de los tres tipos de representaciones). Al contrario de lo que sucede en C4, en C2 la selección de las rocas que se acondicionaron y sobre las que se realizaron los grabados más complejos del sitio tiene una disposición espacial intencional que conforma un espacio circular, que asociamos a un espacio simbólico desde donde se realiza un control visual circular hacia todas las direcciones. Por otro lado, desde allí se conecta el tránsito entre los sectores Oeste y Este y se proyectan líneas de fuga hacia las rocas aisladas más alejadas. En el sentido de Troncoso (2008), la disposición espacial de los bloques incita o domestica el movimiento. El eje principal de tránsito es una ruta donde los conjuntos de rocas son marcadores de movimiento que señalan el camino en una dirección de desplazamiento esteoeste/oeste-este.

Los análisis de visibilidad arqueológica fueron realizados con el propósito de comprender cuál sería la estructura visual del paisaje en relación con las percepciones de los grupos asentados en el sitio La Pampa. El alcance de la visibilidad tiene relación con los aspectos físicos, como en este caso la topografía y la cobertura vegetal del área de estudio; y con los aspectos culturales, como sería el interés selectivo por los objetivos visuales, las posibilidades de desplazarse cuando se mira y la organización cultural del espacio (Criado Boado 1993b). Aunque porciones de la cordillera se ven desde todos los sitios hacia el oeste, desde La Pampa se logra una perspectiva más completa del conjunto imponente que incluye los cerros de más de $5000 \mathrm{~m}$, entre ellos el Tupungato.

El análisis de las cuencas visuales y del tránsito permite acceder a la estrategia social de apropiación del espacio y la forma de construcción del paisaje (Criado Boado 1993b). La estrategia de visibilización, a su vez, está en función de la voluntad de visibilidad, es decir, presupone una determinada actitud hacia el entorno en un contexto cultural determinado.

De acuerdo con estos análisis, La Pampa es un sitio que no tiene conexión visual con los otros de la microrregión: tanto con los asentamientos temporarios del sector cordillerano, más alejados, como con los asentamientos permanentes del oasis pedemontano, más próximos. A pesar de la alta accesibilidad al sitio desde las rutas próximas, la visibilidad es nula desde el corredor del Río de Las Tunas, ya que los soportes no tienen gran impacto visual. Esto hace pensar en un acceso restringido a quienes no tienen un conocimiento previo de su localización. Sin embargo, el sitio domina visualmente cuencas que constituyen potenciales áreas de explotación de recursos y las rutas de desplazamiento 
entre estas cuencas. Esto se puede entender como un modo de legitimación y/o apropiación del espacio.

$\mathrm{Al}$ ampliar la escala de estudio e integrar los contextos del Período Agroalfarero Temprano-medio de la macrorregión conformada por el centro-oeste argentino y Chile central, se puede encontrar mayor afinidad entre las representaciones de La Pampa con el sector trasandino, ya que allí es donde se concentra la mayor cantidad de sitios con "piedras tacitas" alrededor de los $33^{\circ}$ LS (Gajardo Tovar 1959, Planella et al. 2017). Para el caso del área entre el valle de Limarí y el río Maule, Planella et al. (2017) han interpretado su emplazamiento en relación con límites identitarios o demarcaciones territoriales. Como en nuestro caso, las tacitas se relacionan con sociedades de baja escala del Período Alfarero Temprano. Si bien se ha comprobado su uso para prácticas de molienda de vegetales (silvestres y domésticos) y otras actividades de subsistencia en los sitios, datos como la localización de las rocas en las inmediaciones de fuentes de agua y la complejidad de las representaciones que no en todos los casos tendrían una funcionalidad económica, relacionan estos espacios con prácticas ceremoniales supracomunales (Planella et al. 2017).

La combinación de los tres tipos de grabados de La Pampa, sin embargo, no tiene antecedentes conocidos en la macrorregión. Particularmente, las incisiones lineales son las manifestaciones más originales. Los datos sobre la cronología y la funcionalidad del sitio son por el momento relativos, a partir de los componentes artefactuales y su recurrencia en el área. Otros sitios de la cuenca del Río de Las Tunas con morteros se han asociado a actividades domésticas, de obtención y elaboración de alimentos debido a la presencia de otros artefactos de molienda y procesamiento (cerámicos, líticos) y de restos de consumo (Ots 2005, Ots et al. 2016). Sin embargo, los morteros de La Pampa son escasos y de menor tamaño y profundidad, y están asociados a los otros tipos de grabados descritos, por lo que su funcionalidad podría ser distinta a la del procesamiento de alimentos y será indagada con futuros análisis de microdesechos. El conjunto lítico y cerámico es escaso y estaría asociado en parte a la producción de los grabados (desechos con filos naturales y percutores de materias primas duras) y al consumo de alimentos y bebidas, más que a su preparación en el sitio (recipientes cerámicos pequeños, delgados y en baja frecuencia decorados, sin marcas de termoalteración).
Los motivos grabados en las rocas son en su mayoría abstractos, geométricos, y no encontramos patrones en su frecuencia, orientación, ni distribución. Desde nuestra interpretación de los soportes como marcadores del espacio, y en relación con la interpretación del emplazamiento de los grabados macrorregionales, algunos motivos parecerían esculpir formas en las rocas, representaciones abstractas del paisaje (v.g. conexión entre los hoyuelos y las incisiones en LP10, que así pueden contener y transportar líquido desde la cima hasta la base del panel. Fig. 4a). También podrían ser "marcas no-representacionales", resultado de algún tipo de acción "no-visual" sobre la roca con una finalidad que desconocemos (Ouzman 2001).

Aunque por el momento no podemos determinar si los grabados fueron realizados en un único o en sucesivos eventos, la escasez de artefactos en superficie y en distintos niveles de excavación en La Pampa sugiere ocupaciones efímeras, eventuales aunque recurrentes (periódicas, estacionales, anuales), de este espacio. Esto lo distingue del resto de los sitios residenciales y de uso doméstico de la microrregión. Su emplazamiento (en el sentido de Aschero 1997: 18 y ss.) en un sector alejado de aquellos y sin visibilidad desde la ruta que los conecta en la cuenca del Río de Las Tunas, hace suponer un acceso público restringido, acotado a determinadas prácticas no cotidianas y a determinadas personas. Su funcionalidad ceremonial puede interpretarse en relación con las prácticas de agregación social que implicó la producción de los grabados y la realización de rituales asociados con el control y la explotación de los ambientes circundantes conectados por el Río de Las Tunas.

\section{CONCLUSIONES}

En la investigación sobre los grabados rupestres del Río de las Tunas se procuró considerar tres dimensiones espaciales complementarias: la espacial-formal, la simbólica-ritual y la social. El abordaje metodológico para estudiar estas dimensiones fue multiescalar, abarcando el grabado como unidad mínima de análisis, los soportes, la estructuración espacial del sitio y las relaciones contextuales micro y macrorregionales.

Los grabados del sitio La Pampa son particulares tanto en la micro como en la macrorregión centro oeste argentino-Chile central, por lo que su interpretación social no cuenta con marcos de referencia. Mediante 
la metodología de relevamiento y análisis de los datos propuesta, se registraron 794 grabados de distinto tipo y sus asociaciones espaciales en los 25 soportes y en el sitio. Se destaca el uso de una misma tradición técnica para su ejecución, la cual pudo ser compartida por distintas generaciones del componente Alfarero Temprano-medio, fechado en la microrregión entre los siglos v y xiv. A pesar de la proximidad de sitios ocupados durante la dominación incaica regional, no se registraron componentes artefactuales que puedan indicar la reclamación de este sitio durante esa ocupación.

El análisis de la estructura formal del espacio físico se orientó finalmente a interpretar el espacio vivo, dinámico. Así, propusimos una interpretación de cómo los grabados rupestres del sitio La Pampa se integran en el paisaje en una red de relaciones con otros sitios y con otros elementos.

Esta deconstrucción permitió comprender la intencionalidad del emplazamiento del sitio en relación con rutas de tránsito microrregionales, configuradas en torno al cauce principal del área, el Río de Las Tunas. De este modo, el sitio La Pampa demarca la conexión entre sitios de actividades múltiples localizados en dos sectores contrapuestos: la cordillera hacia el oeste y el oasis pedemontano hacia el este. Desde este emplazamiento, se asegura el control visual sobre un amplio marco espacial hacia la cordillera y la planicie, también paisajes contrapuestos.

Finalmente, la integración del registro arqueológico sugiere el uso eventual del sitio en relación con las prácticas de producción de los grabados y con una funcionalidad específica ritual.

Agradecimientos Al Sr. Manuel Cosio, propietario de la finca Gran Espíritu, por su autorización y predisposición para que se pudieran realizar estas investigaciones. A Mariana Raviolo (geóloga), Alejandrina Groissman (fotógrafa), Roberto Bárcena y a los alumnos que participaron de las tareas de campo y laboratorio: Marina Cataldo, Anabel Caniza, Martina Manchado, Gonzalo García, Enrique Gárate, Facundo Quintas, Celina Juárez. A los editores y evaluadores del artículo, cuyas observaciones contribuyeron a mejorarlo.

\section{REFERENCIAS}

Álvarez, M. R. \& Fiore, D. 1995. Recreando imágenes: diseño de experimentación acerca de las técnicas y los artefactos para realizar grabados de arte rupestre. Cuadernos del INAPL 16: 215-239.

Anschuetzs, K., Wilshusen, R. \& Scheick, C. 2001. An archaeology of landscapes: perspectives and directions. Journal of Archaeological Research 9 (2): 152-197.

Arias, P., Crivelli, E., Montero, M., Fernández, M. \& Teira Mayolini, L. C. 2012. Grabados del Holoceno Temprano en la cueva Epullán Grande, Provincia del Neuquén, Argentina: nuevas investigaciones. En Lart pléistocène dans le monde / Pleistocene art of the world / Arte pleistoceno en el mundo. Actes $d u$ Congrès IFRAO, Tarascon-sur-Ariège, septembre 2010-Symposium Art pléistocène dans les Amériques, J. Clottes, Dir., pp. 793-806. Tarascon-sur-Ariège: Société Préhistorique Ariège-Pyrénées.

Aschero, C. 1997. De cómo interactúan emplazamientos, conjuntos y temas. Revista del Museo de Historia Natural XVI (1): 17-28. Mendoza.

BÁrcena, J. R., Roig, F. \& Roig, V. 1985. Aportes arqueo-fitozoológicos para la prehistoria del N.O. de la Provincia de Mendoza: la excavación de Agua de la Tinaja I. Trabajos de Prehistoria 42: 311-363.

Bradley, R., Criado Boado, F. \& Fábregas, R. 1994. Rock art research as landscape archaeology: a pilot study in Galicia, northwest Spain. World Archaeology 25 (3): 374-390.

Cahiza, P. \& OTs, M. J. 2014. Análisis distribucional de sociedades de pequeña escala en el centro oeste argentino. Discusión de las estrategias metodológicas y las interpretaciones en el marco de los estudios regionales. En Distribución espacial en sociedades no aldeanas: del registro arqueológico a la interpretación social, F. Falabella, L. Sanhueza, L. Cornejo \& I. Correa, Eds., pp. 199-219. Sociedad Chilena de Arqueología. Serie Monográfica, 4.

Canals Frau, S. 1956. Algunos aspectos de la cultura de Agrelo (Provincia de Mendoza). Anales de Arqueología y Etnología 12: 7-18.

Criado Boado, F. 1993a. Límites y posibilidades de la arqueología del paisaje. SPAL, Revista de Prehistoria y Arqueología de la Universidad de Sevilla 2: 9-55.

Criado Boado, F. 1993b. Visibilidad e interpretación del registro arqueológico. Trabajos de Prehistoria 50: 39-56.

Criado Boado, F. 1999. Del terreno al espacio. Planteamientos y perspectivas para la arqueología del paisaje. CAPA, 6 . Grupo de Investigaciones en Arqueología del Paisaje. Universidad de Santiago de Compostela.

De Valdivia, L. 1943 [1608]. Vocabulario. Los textos millcayac del Padre Luis de Valdivia (con un vocabulario españolallentiac-millcayac). Estudio y presentación preliminar de F. Márquez. Revista del Museo de La Plata, Tomo II, Antropología 12. Instituto del Museo de la Universidad Nacional de La Plata. 
FÁbrega-Álvarez, P. 2016. Un alto en el camino. Notas acerca del uso de sig en los análisis de movilidad en arqueología. En Manual de tecnologías de la información geográfica aplicadas a la arqueología. Cursos de formación permanente para arqueólogos, M. C. Mínguez \& E. Capdevilla, Coords., pp. 161-182. Madrid: Museo Arqueológico Regional de Madrid.

Fernández Distel, A. 1994. Noticias sobre el sitio arqueológico de Abra de los Morteros y otros lugares de valor prehistórico en la región de Santa Bárbara (Jujuy, República Argentina). En Taller De costa a selva. Producción e intercambio entre los pueblos agroalfareros de Los Andes Centro Sur, M. Albeck, Ed., pp. 255-294. Buenos Aires: Instituto Interdisciplinario Tilcara-Facultad de Filosofía y Letras UBA.

Forman, R. \& Godron, M. 1986. Landscape ecology. Nueva York: John Willey and sons.

GAJARDO, R. 1959. Investigaciones acerca de las "piedras con tacitas" en la zona central de Chile (Comunicación preliminar). Informe sobre los estudios realizados en el fundo Las Cenizas (Placilla-Valparaíso). Anales de Arqueología y Etnología 14-15.

Hermosilla, N. \& Ramírez, J. 1985. Las Cenizas: evidencias de ritualismo en torno a las piedras tacitas. En Actas del IX Congreso Nacional de Arqueología Chilena, pp. 307-320. La Serena: Museo Arqueológico de La Serena.

Lagiglia, H. 1997. Estudio de los petroglifos de Ponontrehue (sur de Mendoza). Actas y Memorias del XI CNAA. Revista del Museo de Historia Natural de San Rafael 13 (1): 269-287.

Oтs , M. J. 2005. Prospección arqueológica de la cuenca del Río de las Tunas (Dptos. Tupungato-Tunuyán, Mendoza). Cuadernos de la Facultad de Humanidades y Ciencias Sociales 29: 43-60.

Oтs, M. J. 2007. La presencia incaica en el Valle de Uco, Mendoza. Tesis para optar al grado de Doctora en Historia. Facultad de Filosofía y Letras, Universidad Nacional de Cuyo.

Ots, M. J., García Llorca, J. \& Cahiza, P. 2016. Recursos y estrategias de consumo en el centro de Mendoza entre los siglos X-XVI AD. Intersecciones en Antropología 17: 375-387.

Ouzman, S. 2001. Seeing is deceiving: rock art and the nonvisual. World Archaeology 33 (2): 237-256.

Planella, M. T., Santander, G. \& Mc Rostie Bustamante, V. 2017. Aportes a la discusión sobre piedras tacitas en Chile central. Intersecciones en Antropología 18: 05-17.

Podestá M., Manzi, L., Horsey, A. \& Falchi, M. 1991. Función e interacción a través del análisis temático en el arte rupestre. En El arte rupestre en la arqueología contemporánea, pp. 40-53. Buenos Aires: Instituto de Arqueología, Facultad de Filosofía y Letras, UBA.

Ponzio, A. \& Reinoso, D. 2013. Los petroglifos de villa El Chacay (Dpto. Río Cuarto, Córdoba) y su relación con el paisaje. Anuario de Arqueología (5): 333-343

Recalde, M. A. 2015. Paisajes con memoria. El papel del arte rupestre en las prácticas de negociación social del sector central de las Sierras de Córdoba (Argentina). En
Condiciones de posibilidad de la reproducción social en sociedades prehispánicas y coloniales tempranas en las sierras pampeanas (República Argentina), J. Salazar, Comp., pp. 235-266. Córdoba: Centro de Estudios Históricos Prof. Carlos S.A. Segreti.

Reyes-García, V., Zurro, D., Caro, J. \& Madella, M. 2017. Small-scale societies and environmental transformations: coevolutionary dynamics. Ecology and Society 22 (1): 15.

RochA, A. 2017a. Grabados rupestres en la cuenca del Río de las Tunas (Valle de Uco, Mendoza). Tesis para optar al grado Licenciado en Historia con orientación en Arqueología. Facultad de Filosofía y Letras. Universidad Nacional de Cuyo.

RochA, A. 2017b. Registro arqueológico de la cuenca media del Río de las Tunas (Valle de Uco, Mendoza): prospecciones y excavaciones en el sitio La Pampa. En Actas de las I Jornadas de Investigación de la Facultad de Filosofía y Letras. Mendoza: Universidad Nacional de Cuyo.

SChobinger, J. 2009. Arqueología y arte rupestre de la región cuyana. Mendoza: Facultad de Filosofía y Letras, Universidad Nacional de Cuyo.

Schobinger, J. \& Gradin, C. 1985. Arte rupestre de la Argentina. Cazadores de la Patagonia y agricultores andinos. Madrid: Encuentro.

Tномаs, J. 2001. Archaeology of place and landscape. En Archaeological theory today, I. Hodder, Ed., pp. 165-186. Cambridge: Cambridge University Press.

Tilley, C. 1996. The powers of rocks: topography and monument construction on Bodmin Moor. World Archaeology 28 (2): $161-176$.

Troncoso M., A. 2008. Arquitectura imaginaria y ritualidad del movimiento: arte rupestre y espacio en el cerro Paidahuen, Chile central. En Sed non satiata II. Acercamientos sociales en la arqueología latinoamericana, F. Acuto \& A. Zarankin, Comps., pp. 277-301. Córdoba: Encuentro.

Troncoso, A., Pino, M. \& Belmar, C. 2017. Piedras tacitas, prácticas socioespaciales, comunidades y paisaje en la cuenca hidrográfica del río Limarí (norte semiárido, Chile). En Actualizaciones en el estudio de piedras tacitas: nuevas perspectivas, C. Belmar, L. Contreras \& O. Reyes, Eds., pp. 67-92. Santiago: Serie Monográfica de la Sociedad Chilena de Arqueología 6.

Valenzuela, D., Briones, L. \& Santoro, C. 2006. Arte rupestre en el paisaje: contextos de uso del arte rupestre en el valle de Lluta, norte de Chile, Períodos Intermedio Tardío y Tardío. En Tramas en la piedra. Producción y usos del arte rupestre, D. Fiore \& M. Podestá, Eds., pp. 205-220. Buenos Aires: Sociedad Argentina de Antropología-Asociación Amigos del INA-World Archeological Congress.

Wheatley, D. \& Gillings, M. 2002. Spatial technology and archaeology. The archaeological application of GIS. Nueva York: Taylor \& Francis. 